University of Wollongong

Research Online

Faculty of Engineering - Papers (Archive)

Faculty of Engineering and Information

Sciences

$1-1-2011$

\title{
Microstructure and mechanical properties after annealing of equal-channel angular pressed interstitial-free steel
}

Sujoy S. Hazra

University of Wollongong, ssh755@uow.edu.au

Elena V. Pereloma

University of Wollongong, elenap@uow.edu.au

Azdiar A. Gazder

University of Wollongong, azdiar@uow.edu.au

Follow this and additional works at: https://ro.uow.edu.au/engpapers

Part of the Engineering Commons

https://ro.uow.edu.au/engpapers/2944

\section{Recommended Citation}

Hazra, Sujoy S.; Pereloma, Elena V.; and Gazder, Azdiar A.: Microstructure and mechanical properties after annealing of equal-channel angular pressed interstitial-free steel 2011, 4015-4029.

https://ro.uow.edu.au/engpapers/2944

Research Online is the open access institutional repository for the University of Wollongong. For further information contact the UOW Library: research-pubs@uow.edu.au 


\title{
Microstructure and Mechanical Properties after Annealing of Equal Channel Angular Pressed Interstitial Free Steel
}

\author{
Sujoy S. Hazra*, Elena V. Pereloma** and Azdiar A. Gazder \\ School of Mechanical, Materials and Mechatronic Engineering, University of Wollongong,
}

New South Wales 2522, Australia

\begin{abstract}
The evolution of microstructure, micro-texture and mechanical properties during isothermal annealing of an ultrafine grained interstitial free (IF) steel after 8 passes, route $\mathrm{B}_{\mathrm{C}}$ room temperature Equal Channel Angular Pressing (ECAP) was studied. The microstructure and micro-texture were characterised by Electron Back-Scattering Diffraction (EBSD) while mechanical properties were assessed by shear punch and uniaxial tensile testing. Homogeneous coarsening via continuous recrystallisation of the ECAP microstructure is accompanied by minor changes in the $\sim 63 \%$ high-angle boundary population and a sharpening of the original ECAP texture. This is followed by abnormal growth during the final stages of softening due to local growth advantages. Linear correlations between shear and tensile data were established for yield, ultimate strengths and total elongation. After yield, the changes in uniaxial tensile behaviour from geometrical softening after ECAP to load drop, Lüders banding and continuous yielding after annealing is attributable to a coarsening microstructure.
\end{abstract}

Keywords: Equal Channel Angular Pressing (ECAP); Electron Back-Scattering Diffraction (EBSD); recrystallization; steels; tension test.

* Presently with R\&D Division, Tata Steel Limited, Jamshedpur - 831007, India

** Corresponding Author: Elena V. Pereloma

Phone: + 612 4221 5507; Fax: + 6124221 3662; $\quad$ Email: elenap@uow.edu.au 


\section{Introduction}

Ultrafine-grained (UFG) materials produced by severe plastic deformation (SPD) processes like Equal Channel Angular Pressing (ECAP) are attractive for their superior room temperature strengths but exhibit poor ductility due to reduced dislocation accumulation ability [1]. Since as-deformed UFG materials are inherently thermodynamically unstable due to their high stored energies caused by lattice defects [2-6], a characterisation of their microstructures and mechanical properties while undergoing a transformation via recovery or recrystallisation is essential.

In terms of annealing behaviour of UFG materials, a variety of phenomena have been reported. Conventional discontinuous recrystallisation was observed by tracking microstructure and crystallographic texture evolution in cold-rolled (CR) $\left(\varepsilon_{\mathrm{vM}}=2.3\right.$ and 4.6) and accumulative roll bonded (ARB) ( $\varepsilon_{\mathrm{vM}}=0.8$ and 4.8) pure $\mathrm{Al}$ [7] with coarse initial grains. A transition from discontinuous to continuous recrystallisation was favoured in CR Al-alloys [8] with small initial grain sizes and large second-phase particles due to a $\sim 65 \%$ high angle grain boundary (HAGB) population, which remained unchanged before and after annealing. Contrarily, High Pressure Torsion (HPT) Ni demonstrated that even a $~ 80 \%$ HAGB population was insufficient to induce the transition from discontinuous to continuous recrystallisation [9]. Emphasising impurity effects on recovery and recrystallisation kinetics, HPT 99.967\% $\mathrm{Ni}$ followed discontinuous recrystallisation while 99.5\% $\mathrm{Ni}$ showed simultaneous continuous and discontinuous recrystallisation [9].

On the other hand, discontinuous recrystallisation in the case of pure $\mathrm{Cu}[10,11]$ and discontinuous growth in Al-alloys [5, 12-14] have been attributed to duplex microstructures with small and large (sub)grains formed after extended annealing or at elevated temperatures.

While literature on the annealing response of room temperature processed bulk UFG steels is lacking, continuous recrystallisation followed by normal grain growth with newly created HAGBs was observed in 304 type austenitic stainless steel statically deformed at $600^{\circ} \mathrm{C}$ by multi-axial compression $\left(\varepsilon_{\mathrm{vM}}=6.4\right)$ [15]. Irrespective of elevated temperature SPD, continuous recrystallisation after annealing also occurred in Ti-IF steels for $\left.200^{\circ} \mathrm{C} \mathrm{ECAP} \mathrm{(route} \mathrm{B}_{\mathrm{A}}{ }^{1}, \varepsilon_{\mathrm{vM}}=9.2\right)$ [16] and $500^{\circ} \mathrm{C} \mathrm{ARB}\left(\varepsilon_{\mathrm{vM}}>4.0\right)$ [17].

With respect to the mechanical properties of UFG materials, phenomena such as: (i) strain softening after yielding during compression of ECAP Ti-IF steel [16] and route C ECAP+CR pure Fe [18]

\footnotetext{
1 When the billet is re-inserted in the entry channel of the ECAP rig and viewed from the top of this channel, route $\mathrm{B}_{\mathrm{A}}$ involves $\mathrm{a}+90^{\circ}$ counter-clockwise (CCW) and a $-90^{\circ}$ clockwise (CW) rotation around its longitudinal axis for successive even and odd numbered passes while route $\mathrm{B}_{\mathrm{C}}$ involves either a $+\mathrm{CCW}$ or $-\mathrm{CW} 90^{\circ}$ rotation (Fig. 1).
} 
was seen in the as-deformed state, (ii) while yield drop and discontinuous yielding was noted in tension after annealing ARB or ECAP commercial purity $\mathrm{Al}[19,20]$, Al-alloys [21] and Ti-IF steel [20].

Furthermore, only limited data on miniature shear punch testing (SPT) [22, 23] of UFG metals in the as-deformed state currently exist [24-26]. The use of SPT as a means to record bulk mechanical property changes during annealing has not yet been applied to UFG materials. Consequently, the correlations between bulk uniaxial tension and SPT shear that enable mechanical property predictions are yet to be quantified.

With the above background, the focus of the present work is two-fold. Firstly, to characterise microstructure evolution and changes in tensile behaviour during isothermal annealing of a room temperature ECAP Ti-stabilised interstitial free (IF) steel at 525, 600 and $710^{\circ} \mathrm{C}$. Secondly, to enable prediction of mechanical properties throughout processing by correlating bulk tension with miniature SPT data.

\section{Experimental and analytical methods}

IF steel (Fe-0.003C-0.15Mn-0.007Si-0.005S-0.01P-0.03Al-0.08Ti-0.001N wt.\%) obtained from BlueScope Steel Ltd. was subjected to room temperature ECAP $\left(\Phi=90^{\circ}, \Psi=0^{\circ}\right)$ using route $\mathrm{B}_{\mathrm{C}}$ up to 8 passes $\left(\varepsilon_{\mathrm{vM}} \sim 9.2\right)$. Further processing details are described in [27-30]. Microstructure, Vickers microhardness $\left(\mathrm{H}_{\mathrm{V}}, \mathrm{VHN}\right)$ and SPT investigations were undertaken on samples cut parallel to the NDED plane from the centre of the stable billet and in the middle of the cross-section (see Fig. 1) using a Struers Accutom-50. $\mathrm{H}_{V}$ was recorded on a M-400-H1 Leco hardness tester at ten random spots on 1 $\mu \mathrm{m}$ diamond suspension polished surfaces using a $500 \mathrm{~g}(4.9 \mathrm{~N})$ load applied for $12 \mathrm{~s}$.

Annealing was performed at $525^{\circ} \mathrm{C}$ for up to 72 hours (h) and at $600^{\circ} \mathrm{C}$ and $710^{\circ} \mathrm{C}$ for up to $5 \mathrm{~h}$, in a salt bath furnace using a Ba-Ca chloride salt (Durferrit GS430 + R2). A reproducible heating rate of $\sim 150( \pm 10){ }^{\circ} \mathrm{C} . \mathrm{s}^{-1}$ was established prior to isothermal holding $\left( \pm 2^{\circ}\right)$ following which the samples were water quenched. The selected annealing temperatures are based on their proximity to the onset, peak and finish temperatures of softening obtained previously via calorimetry [27].

Electropolishing was conducted at room temperature using a Struers Lectropol-3 with a 95\% acetic acid and 5\% perchloric acid electrolyte for $12 \mathrm{~s}$ at $30 \mathrm{~V}$ and a flow rate of 14 flow units (on a full scale of 50). Two EBSD maps for each condition were collected on a JEOL JSM-7001F field emission gun-scanning electron microscope (FEG-SEM) operating at $15 \mathrm{kV}$ excitation voltage, $1.14 \mathrm{nA}$ probe current and fitted with a Nordlys-S camera using the Oxford Instruments Corona Fast Acquisition software. Step sizes between $0.08-1 \mu \mathrm{m}$ were chosen such that they represent $<20 \%$ of the average subgrain size for a particular condition. Post-processing of the maps was undertaken using HKL- 
Channel 5. While an angular resolution limit set constant to $2^{\circ}$ overestimates the HAGB fraction and average misorientation, their overall trend remain unaltered. For micro-texture, $\phi_{2}=0^{\circ}$ and $45^{\circ}$ orientation distribution function (ODF) sections were calculated using Bunge's notation without imposing sample symmetry after exporting EBSD data to MTex [31]. The latter is a Matlab toolbox for texture approximation from EBSD data by kernel density estimation after automatically computing the optimal half-width of the model bell shaped function at every measured individual orientation [31].

Grains (D) surrounded solely by HAGBs $\left(\theta \geq 15^{\circ}\right)$ and subgrains (d) bounded either by low angle boundaries (LAGBs, $2^{\circ} \leq \theta<15^{\circ}$ ) or partially by HAGBs are represented by equivalent circle diameters. Microstructural coarsening was assessed via frequency distributions of $d$ in terms of both, number and area fraction. The number-averaged arithmetic mean $\left(\mathrm{d}_{\text {avg }}\right)$ and standard deviation $\left(\sigma_{d}\right)$ were first calculated. Thereafter the size distribution was fitted to a log-normal (L-N) probability distribution function $\mathrm{p}(\mathrm{d})$ such that:

$$
p(d)=\frac{1}{w d \sqrt{2 \pi}} \exp \left(\frac{\left[\ln \left(d / d_{m}\right)\right]^{2}}{2 w^{2}}\right)
$$

where, $w$ and $d_{m}$ are the width and median of L-N distribution of $d$. Consequently, the associated mean $\left(d_{\text {avg }}^{\mathrm{LN}}\right)$ and standard deviation $\left(\mu_{\mathrm{d}}\right)$ are given as:

$$
\begin{gathered}
d_{\text {avg }}^{\mathrm{LN}}=\mathrm{d}_{\mathrm{m}} \exp \left(\frac{\mathrm{w}^{2}}{2}\right) \\
\mu_{\mathrm{d}}=\mathrm{d}_{\mathrm{m}} \exp \left(\frac{\mathrm{w}^{2}}{2}\right) \sqrt{\exp \left(\mathrm{w}^{2}\right)-1}
\end{gathered}
$$

In this context, $\mathrm{d}_{\mathrm{avg}}^{\mathrm{LN}}$ and $\mu_{\mathrm{d}}$ are computed parameters as opposed to their corresponding experimental counterparts $d_{\text {avg }}$ and $\sigma_{d}$, respectively.

The SPT set-up comprises a $\varnothing 3.01 \mathrm{~mm}$ flat-head punch and $\varnothing 3.018 \mathrm{~mm}$ die. A minimum of two SPT tests per condition were conducted on $\sim 0.8 \mathrm{~mm}$ thick electropolished samples using a custom-built rig fitted to an Instron 5566 operating at a constant cross head speed of $8 \times 10^{-4} \mathrm{~mm} \cdot \mathrm{s}^{-1}$. A $\pm 2.5 \mathrm{~mm}$ linear variable displacement transducer (LVDT) was used to measure compliance corrected displacement. 
For selected conditions, two room temperature tensile tests were undertaken on $15(\mathrm{l}) \times 5(\mathrm{w}) \times 1(\mathrm{t}) \mathrm{mm}^{3}$ wire-cut flat samples at a nominal strain rate of $8 \times 10^{-4} \mathrm{~s}^{-1} \mathrm{using}$ a servohydraulic Instron 1340 equipped with a 33 frames per second video extensometer.

\section{Results}

\subsection{After ECAP}

As shown in Fig. 2(a), the ECAP microstructure consists mostly of slightly elongated (aspect ratio, $\left.\lambda_{d}=2.2-2.6\right)$ subgrains $\left(d_{\text {avg }}=0.44 \mu \mathrm{m}\right)$ and grains $\left(D_{\text {avg }}=0.70 \mu \mathrm{m}\right)$ aligned close to the macroscopic shear direction at $\sim 30-40^{\circ}$ to the ED along with a few areas of equiaxed morphology. This condition corresponds to a high total dislocation density $\left(\rho \square 1.6 \times 10^{15} \mathrm{~m}^{-2}\right.$ [27]), non-uniform localised clustering of LAGBs, a high fraction of HAGBs $\left(\mathrm{f}_{\mathrm{HAGB}}=63( \pm 2) \%\right)$ and an average misorientation $\left(\theta_{\text {avg }}\right)$ of $\sim 27^{\circ}$.

The $\phi_{2}=0^{\circ}$ and $45^{\circ}$ sections of the micro-texture ODF (Fig. 2(b)) is similar to its bulk texture counterpart [32]. The texture components are distributed along the b1, b2 and b3 fibres ([29], represented by black lines) such that the $b 1$ fibre consists of $D_{2 \theta}-E_{\theta} / \bar{E}_{\theta}-D_{1 \theta}^{2}$ orientations along the $\langle 111\rangle_{\theta}$ partial fibre. Similarly the b2 fibre contains $\mathrm{F}_{\theta}-\mathrm{J}_{\theta} / \overline{\mathrm{J}}_{\theta}-\mathrm{E}_{\theta} / \overline{\mathrm{E}}_{\theta}$ orientations (or the $\{110\}_{\theta}$ partial fibre) and $E_{\theta} / \bar{E}_{\theta}-D_{2 \theta}$ orientations (or $\langle 111\rangle_{\theta}$ partial fibre) with a common position at the $\mathrm{E}_{\theta} / \overline{\mathrm{E}}_{\theta}$ orientation. Furthermore, the b3 fibre consists of $\mathrm{F}_{\theta}-\mathrm{J}_{\theta} / \overline{\mathrm{J}}_{\theta}-\mathrm{E}_{\theta} / \overline{\mathrm{E}}_{\theta}$ along the $\{110\}_{\theta}$ partial fibre and $E_{\theta} / \bar{E}_{\theta}-D_{1 \theta}$ along the $\langle 111\rangle_{\theta}$ fibre which once again meet at the common $E_{\theta} / \bar{E}_{\theta}$ position. The major texture components are located near $D_{1 \theta}$ and $E_{\theta} / \bar{E}_{\theta}$ along the $\langle 111\rangle_{\theta}$ fibre and near $\bar{J}_{\theta}$ along the $\{110\}_{\theta}$ fibre. When the ideal texture components are overlaid on the boundary map (Fig. 2(a)) with a $20^{\circ}$ tolerance angle, preferential clustering of orientation components is absent as their spatial distribution remains inhomogeneous.

\section{2 Microstructure evolution during annealing}

In Fig. 3(a) hardness versus annealing time is plotted for 525, 600 and $710{ }^{\circ} \mathrm{C}$ for various isothermal holding times. As expected, higher annealing temperature shifts similar hardness to shorter annealing times. For 525 and $600{ }^{\circ} \mathrm{C}$, two stages are observed such that a gradual fall up to $\sim 190 \mathrm{VHN}$

\footnotetext{
2 In Fig. $1, \theta=\Phi / 2=45^{\circ}$ is the half-angle counter clockwise rotation about the TD of ideal simple shear components in the case of $\Phi=90^{\circ} \mathrm{ECAP}$.
} 
is followed by a comparatively faster decrease up to $\sim 100 \mathrm{VHN}$. In the case of $710{ }^{\circ} \mathrm{C}$, a third stage with hardness decreasing up to and below that of the 0 pass starting material is also seen. The fraction softened (X) shown in Fig. 3(b) can also be expressed in terms of hardness such that:

$$
X=\frac{H_{E}-H_{t}}{H_{E}-H_{0}}
$$

where $H_{E}, H_{t}$ and $H_{0}$ are the hardness after ECAP, instantaneous hardness at time ' $t$ ' and hardness of the 0 pass starting material $(=89.2 \pm 1.3 \mathrm{VHN}$ for $\mathrm{D}=140 \pm 10 \mu \mathrm{m})$, respectively. Here the slope of softening during the first stage increases with higher annealing temperatures and indicates: (i) the dependence of (apparent) activation energy on temperature and, (ii) is characteristic of extensive gradual recovery. Following this, during the second stage the comparatively faster softening rate at higher annealing temperatures or longer times could be ascribed to microstructural coarsening.

Microstructural evolution during annealing and the changes in its associated parameters are illustrated in Figs. 4-6. Compared to the ECAP condition, annealing at 525 and $600{ }^{\circ} \mathrm{C}$ up to $300 \mathrm{~s}$ results in $d_{\text {avg }}$ increasing from 0.44 to $0.61 \mu \mathrm{m}$ with approximately constant $\mathrm{f}_{\text {HAGB }}=62 \%$ and $\theta_{\text {avg }}=27^{\circ}$. Annealing at $525{ }^{\circ} \mathrm{C}$ for up to $5 \mathrm{~h}$ results in further uniform coarsening but the microstructural morphology still closely resembles the ECAP condition with its heterogeneous dispersion of LAGBs. After $72 \mathrm{~h}$, discontinuous coarsening (which is characterised by abnormal grain growth) leads to the formation of a few 5-15 $\mu \mathrm{m}$ large grains (Fig. 4(c)).

At $710^{\circ} \mathrm{C}$ annealing up to $180 \mathrm{~s}$, uniform coarsening is accompanied by increases in $\mathrm{d}_{\text {avg }}=3.5$ $\mu \mathrm{m}, \mathrm{f}_{\mathrm{HAGB}}=71 \%$ and $\theta_{\text {avg }}=32^{\circ}$. After $300 \mathrm{~s}$ and for up to $1 \mathrm{~h}$, discontinuous coarsening results in $\sim 100$ $150 \mu \mathrm{m}$ abnormally grown grains and $\sim 4.5 \mu \mathrm{m}$ uniformly coarsened matrix grains (Fig. 4(i)). Compared to $180 \mathrm{~s}$, no further changes in $\lambda_{\text {avg }}, \mathrm{f}_{\mathrm{HAGB}}$ and $\theta_{\text {avg }}$ were recorded after $1 \mathrm{~h}$.

A recent study on the annealing of an 8 pass route $\mathrm{B}_{\mathrm{C}}$ ECAP Al-0.3Sc alloy showed that L-N distributions were a better theoretical fit than the Rayleigh approach for tracking (sub)grain coarsening [4]. In Fig. 6(a), continuous coarsening is characterised by peak shifts to the right with increasing $d_{\text {avg }}$, decreases in peak frequency and a moderate to significant broadening of the distribution with increasing annealing time or temperature. On the other hand, discontinuous coarsening is marked by the presence of long tails with abnormally grown (sub)grains measuring up to $150 \mu \mathrm{m}$ and small changes to the peak frequency.

If the normalised subgrain size frequency versus $\log \left(\mathrm{d} / \mathrm{d}_{\mathrm{avg}}\right)$ (Fig. $6(\mathrm{~b})$ ) is compared with L-N plots, the invariant nature of both subgrain size distributions is clearly evident with their extended 
tails representing discontinuous coarsening. Similar observations on the general form of subgrain size distribution have been made on annealed ECAP Al alloys [4, 13, 14].

On plotting the experimental arithmetic mean and standard deviations against their computed counterparts (Fig. 6(c)), linearity is maintained during continuous coarsening as both values match closely. Notable deviations from log-normality only occur during discontinuous coarsening at $710{ }^{\circ} \mathrm{C}$ beyond $180 \mathrm{~s}$. Interestingly, in the case of the few abnormally large grains seen after $525^{\circ} \mathrm{C}$ annealing for $72 \mathrm{~h}$, the deviation from linearity is minimal.

For further explanation, the area-weighted size distribution (Fig. 7) can be used. If the tail of the left (or continuously coarsened) and head of the right (or discontinuously coarsened) - side of these distributions are intersected, the critical cut-off size beyond which discontinuous coarsening occurs could be estimated as seen in the transition case of at $710^{\circ} \mathrm{C}$ for $180 \mathrm{~s} \mathrm{(Fig.} 7$ (b)). Consequently, $\sim 3 \mu \mathrm{m}$ at $525^{\circ} \mathrm{C}$ for $72 \mathrm{~h}$ (Fig. 7(a)), 8, 10 and $20 \mu \mathrm{m}$ at $710^{\circ} \mathrm{C}$ for $180 \mathrm{~s}, 300 \mathrm{~s}$ and $1 \mathrm{~h}$ (Figs. 7(b-d)), respectively are seen as the cut-offs between the continuously coarsened matrix and large discontinuously grown (sub)grains.

If we assume that the driving pressure for coarsening arises from boundary curvature, isothermal subgrain coarsening kinetics can be derived such that [33]:

$$
\mathrm{d}_{\text {avg }}{ }^{\mathrm{n}}=\mathrm{kt}
$$

or

$$
\log \left(\mathrm{d}_{\mathrm{avg}}\right)=\frac{1}{\mathrm{n}} \log (\mathrm{t})+\mathrm{c}
$$

where, $\mathrm{n}$ is subgrain growth exponent, $\mathrm{k}$ is a temperature dependent rate constant and $\mathrm{c}=(1 / \mathrm{n}) \log (\mathrm{k})$. During normal grain growth following primary recrystallisation, $\mathrm{n}=2$ is predicted based on either the proportionality of the growth rate to the interfacial free energy per unit volume or the inverse proportionality of boundary migration rate to the boundary curvature [34]. However, larger experimentally determined exponents between 3-10 have been reported for single phase materials [35] with $\mathrm{n}$-values showing an inverse trend with temperature and purity level.

In the present case, for 525 and $600{ }^{\circ} \mathrm{C}$ annealing $\mathrm{n}$-values range between 5 and 13 (Fig. 6(d)). At $710^{\circ} \mathrm{C}$, faster kinetics with $\mathrm{n}=1$ are recorded for the first stage up to $30 \mathrm{~s}$. Thereafter sluggish growth rates with $\mathrm{n} \sim 10$ are calculated in accordance with the microstructure evolving via coarsening by recovery-like processes. This is further evidenced by the ODFs presented for longest investigated annealing times which show the preservation (Figs. 8(a-c)) and sharpening (Fig. 8(d)) of negative simple shear texture components even after prolonged annealing. It may be noted that the trend of near $D_{1 \theta}$ texture component being stronger than the $D_{2 \theta}$ component after ECAP prevailed during 
uniform coarsening (compare Figs. 2(b) and 8(b)). On the other hand, during non-uniform coarsening the opposite trend in the evolution of stronger $D_{2 \theta}$ texture component is evident from Figs. 8(a) and (c). However, it should be kept in mind that when compared against the as-ECAP condition, the relative shifts and spreads of the texture components away from their ideal positions during annealing may arise due to micro-texture measurements. Lastly, since $\mathrm{n}$ varies with temperature, the apparent activation energy for growth cannot be determined using Eq. 6 .

\section{3 Changes in mechanical properties}

Figs. 9(a-c) depict the SPT curves for the 0 pass starting material, after ECAP and after 525, 600 and $710{ }^{\circ} \mathrm{C}$ for various isothermal holding times. The shear stress $(\tau)$ and normalised displacement $(\delta$ ) were determined from the load-displacement data using [22]:

$$
\begin{aligned}
& \tau=\frac{\text { Load }}{\pi^{*} \Delta_{\text {avg }} * \text { thickness }} \\
& \delta=\frac{\text { displacement }}{\text { thickness }}
\end{aligned}
$$

where, $\Delta_{\text {avg }}$ is the average punch and die diameters. Tensile engineering stress versus strain plots for the 0 pass starting material, after ECAP [36] and that of selected annealing temperatures are shown in Fig. 9(d). Subgrain/grain refinement via ECAP results in increased strengths and reduced ductility while microstructural coarsening during annealing is marked by a loss in strength and return of ductility. In terms of achieving a strength-ductility balance, annealing at $710{ }^{\circ} \mathrm{C}, 15 \mathrm{~s}$ resulted in $\sigma_{0.2 \%}=$ $338 \mathrm{MPa}, \sigma_{\text {UTS }}=374 \mathrm{MPa}, \mathrm{e}_{\mathrm{u}}=22 \%$ and $\mathrm{e}_{\mathrm{f}}=33 \%$ when a grain size of $\sim 2.5 \mu \mathrm{m}$ is reached.

Since the SPT curves indicate a smooth transition between elastic and plastic regions, a $0.5 \%$ offset of the shear normalised displacement $(\delta)$ is used to approximate the shear yield stress $\left(\tau_{0.5 \%}\right)$ as it returned the best overall correlation. This is less than the $1 \%$ offset reported earlier [22, 37] as the precise measurement of the punch tip displacement by the LVDT largely eliminated machine compliance above the sample surface. Consequently, no further compliance corrections were necessary.

For the tensile curves, yield stress $\left(\sigma_{\mathrm{YS}}\right)$ is defined as either: (i) the $0.2 \%$ strain offset value in the case of continuous yielding or, (ii) the lower yield stress during discontinuous yielding. The maximum shear stress $\left(\tau_{\max }\right)$ and tensile UTS $\left(\sigma_{\text {UTS }}\right)$ are computed from the maximum loads during SPT and tensile testing, respectively. 
In order to derive the linear correlations for $\sigma_{\mathrm{YS}}-\tau_{0.5 \%}, \sigma_{\mathrm{UTS}}-\tau_{\max }$ and total tensile elongation $\left(\mathrm{e}_{\mathrm{f}}\right)$ - maximum normalised displacement in shear $\left(\delta_{\max }\right)$ over a wider range of UFG sub(grain) sizes for the same IF steel, additional data points were obtained from the ECAP billet subjected to additional cold rolling for up to $95 \%$ thickness reduction. Thereafter, the mechanical properties were ascertained by SPT and tensile testing [36].

The correlation between $\sigma_{\mathrm{YS}}$ and $\tau_{0.5 \%}$ is illustrated in Fig. 10(a) such that:

$$
\sigma_{\mathrm{YS}}=(1.77 \pm 0.09) * \tau_{0.5 \%}
$$

According to the von Mises yield criterion for pure shear of kinematically hardening materials, the correlation coefficient between uniaxial and pure shear yield stress is $\sqrt{3}$. The present value of 1.77 is close to the theoretical one, is the same as reported in [22] and is within the 1.6-2.5 range obtained from SPT for other metals/alloys [37, 38]. The small deviation from theoretical value can be attributed to the complex stress state other than pure shear in the annular region of the punched-out disc where material shears off during the test $[22,38]$.

Separate correlations have been obtained for the deformed (Fig. 10(b)) and annealed conditions (Fig. 10(c)) between $\sigma_{\text {UTS }}$ and $\tau_{\max }$ such that:

$$
\begin{aligned}
& \text { Deformed: } \sigma_{\text {UTS }}=(1.69 \pm 0.10) * \tau_{\max } \\
& \text { Annealed: } \sigma_{\text {UTS }}=(1.29 \pm 0.08) * \tau_{\max }
\end{aligned}
$$

The separation between deformed and annealed conditions was undertaken based on their varying abilities to work harden. In the case of brittle materials, the correlation coefficient between $\sigma_{\mathrm{UTS}}$ and $\tau_{\max }$ is $\sim 1.73$ while for a ductile material, the value reduces to $\sim 1.10$ [39]. In agreement with the above expectation, IF steel returned 1.69 for the deformed state and 1.29 after annealing.

Similarly, the correlations between $\mathrm{e}_{\mathrm{f}}$ and $\delta_{\max }$ are described by two linear fits (Fig. 10(d)):

$$
\begin{aligned}
& \text { Deformed (I): } \mathrm{e}_{\mathrm{f}}=(0.12 \pm 0.01) * \delta_{\max } \\
& \text { Annealed (II): } \mathrm{e}_{\mathrm{f}}=(2.21 \pm 1.39) * \delta_{\max }-(146.2 \pm 100)
\end{aligned}
$$

The regions I and II are below and above the $\sim 70 \% \delta_{\max }$-value as it represents a transition between two linear regions. Using the above equations, the yield, tensile strengths and total elongations can now be predicted for any new processing schedule. 


\section{Discussion}

\subsection{Coarsening behaviour}

The annealing of cold worked single phase materials deformed to medium to high strains $\left(\varepsilon_{\mathrm{vM}}=3.5\right)$ is conventionally accompanied in turn by thermally activated processes of: (i) recovery, (ii) primary or discontinuous recrystallisation and, (iii) normal or abnormal (or secondary recrystallisation) grain growth $[40,41]$.

Recovery includes all annealing processes occurring without any HAGB migration. On the other hand, discontinuous recrystallisation is due to non-uniformly dispersed nuclei formation and subsequent new grain formation by the creation and migration of HAGBs. Here all sub-processes are driven by differences in local stored energy. During the grain growth period, the migration of grain boundaries is solely accomplished by a curvature-driven reduction of boundary area. Under circumstances of normal grain growth, the average grain size increases gradually. However, when grain coarsening is inhomogeneous and a few isolated grains grow larger than the average recrystallised matrix, the phenomenon is termed as abnormal grain growth. Consequently, discontinuous recrystallisation results in the replacement of the deformation texture by a new recrystallisation texture.

In the present investigation, IF steel was deformed via room temperature ECAP to $\varepsilon_{\mathrm{vM}} \sim 9.2$ and subsequently annealed. Irrespective of annealing temperature, the onset of softening was gradual and without an incubation period and occurred uniformly over an extended time interval. Similar softening behaviour is found in particle containing $\mathrm{Al}$ alloys where boundary pinning by second phase particles inhibits discontinuous recrystallisation via extended recovery resulting in microstructures with large dislocation-free subgrains surrounded by LAGBs [40].

Due to the high fraction of strain-induced HAGBs ( 62\%) after ECAP, homogeneous softening (or continuous recrystallisation) occurs without a discernible nucleation and growth sequence upon annealing [40]. Since recovery is predominant, the distinction between extended recovery and continuous recrystallisation is made based on both the character and mobility of the boundaries [40]. It has been proposed that extended recovery corresponds to softening accompanied by immobile HAGBs, while continuous recrystallisation involves HAGB migration [41]. Furthermore, during continuous recrystallisation the original deformation texture is maintained and becomes sharper and is concurrent with recovery mechanisms comprising short-range dislocations and boundary migration [41]. 
After annealing at $525{ }^{\circ} \mathrm{C}$ for $72 \mathrm{~h}$ (see Fig. 4(c)), the microstructure comprised large areas of uniformly coarsened grains with the (sub)grain morphology similar to ECAP. Abnormally large grains $\left(\mathrm{d}_{\max } / \mathrm{d}_{\text {avg }} \sim 13\right)$ surrounded primarily by HAGBs were restricted to a few local areas. Such location dependent coarsening is linked to macroscopic substructural heterogeneities carried over from ECAP. Consequently, the local recovery rate will be dictated by the balance between dynamic recovery during ECAP and the stored energy difference. While such localised abnormal grains produce a tail in the L-N distribution (Fig. 6(a)), the $d_{\text {avg }}, \lambda_{\text {avg }}, f_{\text {HAGB }}$ and $\theta_{\text {avg }}$-values remain unaltered. It follows that no deviations away from linearity should be expected when plotting their average and computed (sub)grain sizes (see Fig. 6(c)).

At $600{ }^{\circ} \mathrm{C}$, similar recovery and growth stages via uniform coarsening were observed for up to $5 \mathrm{~h}$ annealing (see Fig. 4(f)). Considering that the transition to abnormal growth occurred at 525 and $710^{\circ} \mathrm{C}$ at varying times, such non-uniform coarsening should be expected beyond $5 \mathrm{~h}$.

During $710{ }^{\circ} \mathrm{C}$ annealing for $30 \mathrm{~s}$, the transition to a uniform and equiaxed microstructure is accompanied by a change in subgrain growth kinetics from $\mathrm{n} \sim 1$ to 10 . The faster kinetics up to $30 \mathrm{~s}$ result in sharp increases in $d_{\text {avg }}$ and decreases in $\lambda_{\text {avg }}$-values (see Figs. 5(a-b) ) while much slower growth kinetics prevail up to complete softening. After $300 \mathrm{~s}$ (see Fig. 4(i)) the microstructure comprises a location dependent $\sim 20 \%$ area fraction of abnormally large grains $\left(d_{\max } / d_{\text {avg }} \sim 28\right)$ primarily surrounded by HAGBs and a uniformly coarsened matrix with LAGB clusters. In this particular case of $300 \mathrm{~s}$, the heterogeneous dispersion of abnormal grains was also confirmed by EBSD over a scan area of $\sim 7 \times 0.2 \mathrm{~mm}^{2}$. After $1 \mathrm{hr}$ (see Fig. 4(j)), $\sim 80 \%$ of the map area is covered by the abnormally large grains $\left(\mathrm{d}_{\max } / \mathrm{d}_{\text {avg }} \sim 38\right)$ as they consumed a significant fraction of surrounding matrix grains.

It is noteworthy that irrespective of annealing temperature and holding time, orientation preference could not be ascertained: (i) between LAGB clusters within the uniformly coarsened matrix or, (ii) between the abnormally large gains and the neighbouring matrix. Consequently, the formation of these abnormally large grains can be attributed to local growth advantages dictated by the presence of low mobility LAGBs in their neighbourhood. Boundary pinning effects on the formation of these abnormal grains can also be ruled out as the volume fraction $\left(\sim 10^{-4}\right)$ of TiC precipitates in clean interstitial free steels is insignificant to cause Zener pinning [27, 42].

In summary, the annealing of our UFG steel can be appropriately categorised as continuous recrystallisation followed by abnormal growth. While continuous recrystallisation with a slight bimodality in sizes has been reported during the annealing of an IF-steel subjected to 8 passes, route $\mathrm{B}_{\mathrm{A}}, 200^{\circ} \mathrm{C} \mathrm{ECAP}$, abnormal growth did not occur even after extended annealing at $500{ }^{\circ} \mathrm{C}$ for $128 \mathrm{~h}$ and 
$600{ }^{\circ} \mathrm{C}$ for $100 \mathrm{~h} \mathrm{[16].} \mathrm{The} \mathrm{variation} \mathrm{in} \mathrm{the} \mathrm{two} \mathrm{results} \mathrm{could} \mathrm{be} \mathrm{attributed} \mathrm{to} \mathrm{the} \mathrm{combined} \mathrm{effects} \mathrm{of}$ dynamic recovery during elevated temperature ECAP and the processing route-dependent $\mathrm{f}_{\text {HAGB }}$ value (which is $\sim 9 \%$ lower in the present study than in [16]).

\subsection{Characteristics of SPT and tensile curves}

If the SPT and tensile curves are compared, the former curves show: (i) an absence of discontinuous yielding and, (ii) an inherently exaggerated work hardening tendency between yield to maximum stress [37].

During blanking/shearing operations, the annular shear zone is nominally subjected to a combination of relatively uniform shear and varying contributions from compressive, tensile and bending stresses $[22,38]$. In this context, the $4 \mu \mathrm{m}$ die-punch clearance (or $0.5 \%$ of $\sim 0.8 \mathrm{~mm}$ blank thickness) of the present SPT set-up enables the imposition of an 'apparent' state of pure shear [43, $44]$ by reducing the bending and tensile stress components associated with blanking/shearing. This is clearly evident from the smooth surface of the slug (Fig. 11(a)).

The ability of SPT to exhibit discontinuous yielding (analogous to Lüders banding in tension) was shown in solution-annealed low carbon steel [37]. For the same condition (see Fig. 3 in [37]), discontinuous yielding extended over $\sim 2 \%$ of the normalised displacement in SPT and $\sim 5 \%$ of the engineering strain in tension. Secondly, the appearance of discontinuous yielding during SPT in [37] is due to the larger die-punch clearance $(\sim 12 \%$ of blank thickness). Larger punch-die clearances increase the contribution of the tensile stress component during bending after the punch penetrates the blank surface and leads to an uneven transition between the elastic and plastic regions of the curve. Since the punch-die clearance in this study was restricted to $0.5 \%$ of the blank thickness and the maximum extent of discontinuous yielding was only $\sim 2 \%$ of the engineering strain, it is plausible that discontinuous yielding was suppressed in the SPT curves.

The tensile curves (Fig. 9(d)) are discussed on the basis of grain size ( $D_{\text {avg }}$ ) such that their characteristic evolution is similar to earlier annealing reports on 8 passes, route $\mathrm{B}_{\mathrm{C}} \mathrm{ECAP} \mathrm{Al}$ [19] and ARB Ti-IF steel and commercially pure Al [20]. For grain sizes smaller than $0.7 \mu \mathrm{m}$, the uniform elongation $\left(\mathrm{e}_{\mathrm{u}}\right)$ up to UTS is $\sim 1-2 \%$ and subsequent failure by local necking accompanying geometrical softening. For grain sizes between 0.7-1.5 $\mu \mathrm{m}$, the curves are characterised by a yielddrop where necking occurs soon after yielding. The extent of load drop decreases with increasing grain size (see 0.9 and $1.1 \mu \mathrm{m}$ ), and is similar to annealed UFG Al and can be related to the formation of conjugate shear bands immediately after yielding $[19,45]$. In the case of $0.9 \mu \mathrm{m}$, the restricted work hardening capacity after yielding and $\sim 8 \%$ total elongation is highlighted by the smooth surface of the tensile specimen near the fracture (Fig. 11(b)). 
Between grain sizes of 1.5-2.5 $\mu \mathrm{m}$ the discontinuously yielded tensile curves evolve from being close to elastic-perfectly plastic to exhibiting work hardening prior to necking. The rough appearance of the tensile surface (Fig. 11(c)) of the $D_{\text {avg }}=2.3 \mu \mathrm{m}$ sample is indicative of $e_{f} \sim 35 \%$ via extensive deformation.

Upon reaching an average grain size of $4.1 \mu \mathrm{m}$, the transition to continuous yielding is complete with the absence of Lüders banding from the discontinuously coarsening microstructure for $710{ }^{\circ} \mathrm{C}, 300 \mathrm{~s}$. The non-representative nature of the average grain size $\left(D_{\text {avg }}=4.1 \mu \mathrm{m}\right)$ becomes immediately apparent when its strength values are compared with the 0 pass starting material $\left(D_{\text {avg }}=140 \mu \mathrm{m}\right)$ and corroborates the observations by large area $\left(\sim 7 \times 0.2 \mathrm{~mm}^{2}\right)$ EBSD mapping of this condition. Here pockets of 3-4 mm lengths containing large grains $\left(D_{\text {avg }}=90-100 \mu \mathrm{m}\right)$ were observed.

The fractographs of all tensile samples show dimples of varying sizes and shapes which is characteristic of ductile fracture. As a representative example, the $2.3 \mu \mathrm{m}$ grain size sample indicates coalesced voids and Ti-rich nitride precipitates (Fig. 11(d)).

With respect to the above results, the manifestation of inhomogeneous yielding (as either yield-drop or Lüders banding) in clean Ti-IF steel appears to be grain size dependent. Similar behaviour has been observed during room temperature tensile testing of annealed ARB Ti-IF steel up to $2 \mu \mathrm{m}[20]$ and annealed ECAP commercial purity Al up to $4 \mu \mathrm{m}$ [19].

Such material independent behaviour in clean metals is indicative of inhomogeneous flow due to the scarcity of mobile dislocations in UFG microstructures rather than their interactions with solute atoms $[19,46]$. As a consequence, it could be possible that mobile dislocations near grain boundaries after ECAP sustain the applied strain rate during subsequent tensile testing without a yield-drop [19, 47]. After initial annealing at longer times at lower temperature (for example, $525^{\circ} \mathrm{C}, 5 \mathrm{~h}$ ) or shorter times at higher temperature $\left(610^{\circ} \mathrm{C}, 300 \mathrm{~s}\right.$ or $\left.710^{\circ} \mathrm{C}, 5 \mathrm{~s}\right)$, the annihilation of these mobile dislocations causes a yield-drop as a result of their shortage to fulfil the applied strain rate. The transition from yield-drop to Lüders banding between 1.5-2.5 $\mu \mathrm{m}$ grain sizes is based on the dislocation sink effect at grain boundaries [19, 48-50]. If the above inhomogeneous phenomena are assumed to be controlled by dislocations emitted from grain boundaries rather than just by intra-granular sources, an increase in dislocation sinks is inevitable due to the net increase in grain boundary surface area [51]. The latter in turn leads to a decrease in the area swept by mobile dislocations. During tensile testing of annealed microstructures whose average grain sizes are still comparable to the (sub)grain size after ECAP, the reduction in mobile dislocation density is unable to sustain the rate of imposed strain. Consequently, a sudden increase in their velocities results in higher stresses and the appearance of a yield peak. Thereafter, with even further annealing and microstructural coarsening, a return to continuous 
yielding and subsequent work hardening is due to the ability of larger grains to generate dislocations in their interiors.

It is also emphasised that the size dependent appearance of inhomogeneous yielding in UFG metals is not only influenced by test temperature and grain boundary character [47] but also by the grain size distribution [52]. Since the grain boundary character and size distribution remained almost time-temperature invariant in the cases where inhomogeneous yielding was noted, their effects can be discarded.

\section{Conclusions}

Microstructure and mechanical property characterisation of 8 pass, route $\mathrm{B}_{\mathrm{C}}$ ECAP Ti-IF steel subjected to isothermal annealing at 525,600 and $710{ }^{\circ} \mathrm{C}$ was undertaken. The microstructure underwent coarsening by continuous recrystallisation followed by abnormal growth. Continuous recrystallisation is evidenced by the invariant nature of the log-normal subgrain size distribution and the retention and sharpening of the deformation texture. Abnormal growth occurs during the final stages of softening via local growth advantages.

Using a $0.5 \%$ offset (SPT) criteria, the correlation coefficient for yield between shear punch and tensile testing was close to theory at 1.77. Correlations for the maximum load after ECAP resembled that of brittle materials at 1.69 , while the value reduced to 1.29 upon annealing. Separate correlations were also derived for predicting total elongation.

Grain size dependent evolution of uniaxial tensile behaviour was noted such that geometrical softening after ECAP was replaced by load drop, Lüders banding and finally, a return to continuous yielding and work hardening upon annealing.

\section{Acknowledgements}

SSH is grateful to Tata Steel, India for study leave.

\section{References}

[1] Bouaziz O, Estrin Y, Bréchet Y, Embury JD. Scr. Mater. 2010;63:477.

[2] Driver JH. Scr. Mater. 2004;51:819.

[3] Zahid GH, Huang Y, Prangnell PB. Acta Mater. 2009;57:3509.

[4] Ferry M, Burhan N. Acta Mater. 2007;55:3479. 
[5] Ferry M, Hamilton NE, Humphreys FJ. Acta Mater. 2005;53:1097.

[6] Vorhauer A, Pippan R. Metall. Mater. Trans. A 2008;39:417.

[7] Cao WQ, Godfrey A, Hansen N, Liu Q. Metall. Mater. Trans. A 2009;40:204.

[8] Jazaeri H, Humphreys FJ. Acta Mater. 2004;52:3251.

[9] Zhang HW, Huang X, Pippan R, Hansen N. Acta Mater. 2010;58:1698.

[10] Molodova X, Gottstein G, Winning M, Hellmig RJ. Mater. Sci. Eng. A 2007;460-461:204.

[11] Molodova X, Khorashadizadeh A, Gottstein G, Winning M, Hellmig RJ. Int J Mater Res 2007;4:269.

[12] Cao WQ, Godfrey A, Liu W, Liu Q. Mater Sci Eng. A 2003;360:420.

[13] Morris DG, Muñoz-Morris MA. Acta Mater. 2002;50:4047.

[14] Yu CY, Sun PL, Kao PW, Chang CP. Mater Sci Eng. A 2004;366:310.

[15] Belyakov A, Sakai T, Miura H, Kaibyshev R, Tsuzaki K. Acta Mater. 2002;50:1547.

[16] De Messemaeker J, Verlinden B, Humbeek JV. Mater. Sci. Forum 2004;467-470:1295.

[17] Tsuji N, Kamikawa N, Minamino Y. Mater. Sci. Forum 2004;467-470:341.

[18] Wei Q, Kecskes L, Jiao T, Hartwig KT, Ramesh KT, Ma E. Acta Mater. 2004;52:1859.

[19] Yu CY, Kao PW, Chang CP. Acta Mater. 2005;53:4019.

[20] Tsuji N, Ito Y, Saito Y, Minamino Y. Scr. Mater. 2002;47:893.

[21] Xing ZP, Kang SB, Kim HW. J. Mater. Sci. 2004;39:1259.

[22] Guduru RK, Darling KA, Kishore R, Scattergood RO, Koch CC, Murty KL. Mater Sci Eng. A 2005;395:307.

[23] Lucas GE, Sheckherd JW, Odette GR, Panchanadeeswaran S. J Nucl Mater 1984;122:429.

[24] Alizadeh R, Mahmudi R. Mater. Sci. Eng. A;527:3975.

[25] Masoudpanah SM, Mahmudi R. Mater. Design.;31:3512.

[26] Hosseini SM, Najafizadeh A, Kermanpur A. J. Mater. Process. Tech.;211:230.

[27] Hazra SS, Gazder AA, Pereloma EV. Mater. Sci. Eng. A 2009;524:158.

[28] Hazra SS, Gazder AA, Pereloma EV. Adv. Mater. Res. 2010;89-91:244.

[29] Li S, Gazder AA, Beyerlein IJ, Davies CHJ, Pereloma EV. Acta Mater. 2007;55:1017.

[30] Li S, Gazder AA, Beyerlein IJ, Pereloma EV, Davies CHJ. Acta Mater. 2006;54:1087.

[31] Hielscher R, Schaeben H. J. Appl. Crystallogr. 2008;41:1024.

[32] Gazder AA. The Mechanical, Microstructure and Texture properties of Interstitial Free steel subjected to Equal Channel Angular Extrusion, PhD Thesis. Melbourne, Australia: Monash University, 2007.

[33] Beck PA, Kremer JC, Deer LJ, Holzworth ML. Trans. AIME 1948;175:372.

[34] Burke JE, Turnbull D. Progress in Metal Physics 1952;3:220.

[35] Gottstein G, Shvindlerman L. Grain boundary migration in metals: Thermodynamics, kinetics, applications. Boca Raton, FL: CRC Press, Taylor \& Francis Group, 2009.

[36] Hazra SS, Gazder AA, Carman A, Pereloma EV. Metall. Mater. Trans. A 2010;doi: 10.1007/s11661010-0535-5. 
[37] Toloczko MB, Kurtz RJ, Hasegawa A, Abe K. J Nucl Mater 2002;307-311:1619.

[38] Hankin GL, Toloczko MB, Hamilton ML, Faulkner RG. J Nucl Mater 1998;258-263:1651.

[39] Karthik V, Visweswaran P, Vijayraghavan A, Kasiviswanathan KV, Raj B. J Nucl Mater 2009;393:425.

[40] Humphreys FJ, Hatherly M. Recrystallization and related annealing phenomena. Oxford: Pergamon Press, 2004.

[41] Doherty RD, Hughes DA, Humphreys FJ, Jonas JJ, Jensen DJ, Kassner ME, King WE, McNelley TR, McQueen HJ, Rollett AD. Mater Sci Eng. A 1997;238:219.

[42] Choi J-Y, Seong B-S, Baik SC, Lee HC. ISIJ 2002;42:889.

[43] Gotoh M, Yamashita M. J. Mater. Process. Tech. 2001;110:253.

[44] Tekiner Z, Nalbant M, Gürün H. Mater. Design. 2006;27:1134.

[45] Hung PC, Sun PL, Yu CY, Kao PW, Chang CP. Scr. Mater. 2005;53:647.

[46] Wyrzykowski JW, Grabski MW. Mater Sci Eng. 1982;56:197.

[47] Sun PL, Yu CY, Kao PW, Chang CP. Scr. Mater. 2005;52:265.

[48] Cheng S, Spencer JA, Milligan WW. Acta Mater. 2003;51:4505.

[49] Li YJ, Mueller J, Höppel HW, Göken M, Blum W. Acta Mater. 2007;55:5708.

[50] Hayes RW, Witkin D, Zhou F, Lavernia EJ. Acta Mater. 2004;52:4259.

[51] Johnston WG, Gilman JJ. J. Appl. Phys. 1959;30:129.

[52] Terada D, Houda H, Tsuji N. J Phys Conf Ser 2010;240:012111. 


\section{List of Figures}

Fig. 1: Schematic representation of the ECAP coordinate system and the billet being re-inserted in the entry channel for successive passes via routes $B_{A}$ and $B_{C}$. $E D=$ extrusion direction, $R D=$ rolling direction, $\mathrm{TD}=$ transverse direction, $\mathrm{ND}=$ normal direction.

Fig. 2: (a) Representative EBSD grain boundary maps overlaid with ideal negative simple shear texture components and, (b) $\phi_{2}=0^{\circ}$ and $\phi_{2}=45^{\circ} \mathrm{ODF}$ sections of the micro-texture after ECAP. In (a), red (grey) $=$ LAGBs, black $=$ HAGBs. Contour levels $=1 \times$ random.

Fig. 3: (a) Hardness versus annealing time and, (b) fraction softened versus annealing time for isothermal annealing at 525,600 and $710^{\circ} \mathrm{C}$.

Fig. 4: Representative EBSD grain boundary maps after annealing at (a-c) $525^{\circ} \mathrm{C}$, (d-f) $600{ }^{\circ} \mathrm{C}$ and (g-j) $710{ }^{\circ} \mathrm{C}$ for: (a) $300 \mathrm{~s}$, (b) $5 \mathrm{~h}$, (c) $72 \mathrm{~h}$, (d) $300 \mathrm{~s}$, (e) $1 \mathrm{~h}$, (f) $5 \mathrm{~h}$, (g) $30 \mathrm{~s}$, (h) $180 \mathrm{~s}$, (i) $300 \mathrm{~s}$ and (j) $1 \mathrm{~h}$. Red (grey) $=$ LAGBs, black $=$ HAGBs.

Fig. 5: Evolution of (a) subgrain size, (b) aspect ratio, (c) HAGB fraction and, (d) average misorientation during isothermal annealing at 525,600 and $710^{\circ} \mathrm{C}$.

Fig. 6: (a) Fitted L-N subgrain size distributions, (b) normalised subgrain size distributions, (c) experimental versus computed arithmetic mean and standard deviation of subgrain size distributions and, (d) subgrain growth kinetics during isothermal annealing at 525, 600 and $710{ }^{\circ} \mathrm{C}$. In (b), the arrow marks the tail of the L-N distributions.

Fig. 7: Evolution of area-weighted grain size distribution after annealing at (a) $525^{\circ} \mathrm{C}$ for $72 \mathrm{~h}$ and, 710 ${ }^{\circ} \mathrm{C}$ for (b) $180 \mathrm{~s}$ (c) $300 \mathrm{~s}$ and, (d) $1 \mathrm{~h}$. Note that arrows indicate the critical cut-off subgrain size beyond which discontinuous coarsening occurs.

Fig. 8: $\phi_{2}=0^{\circ}$ and $\phi_{2}=45^{\circ} \mathrm{ODF}$ sections of the micro-texture after annealing at (a) $525^{\circ} \mathrm{C}$ for $72 \mathrm{~h}$, (b) $600{ }^{\circ} \mathrm{C}$ for $5 \mathrm{~h}$, (c) $710^{\circ} \mathrm{C}$ for $5 \mathrm{~h}$ and, (d) maximum ODF intensity $\mathrm{f}(\mathrm{g}$ ) versus annealing time. Contour levels $=1 \times$ random.

Fig. 9: Shear stress versus normalised displacement after shear punch testing for (a) 0 pass starting, ECAP and $525^{\circ} \mathrm{C}$, (b) $600{ }^{\circ} \mathrm{C}$, (c) $710{ }^{\circ} \mathrm{C}$ and, (d) engineering stress versus strain after tensile testing for various conditions. Note the average grain diameters in (d).

Fig. 10: Correlations between (a) shear and tensile yield strengths, (b) maximum shear and ultimate tensile strengths after deformation, (c) maximum shear and ultimate tensile strengths after annealing and, (d) total elongation in tension with maximum normalised displacement in shear. 
Fig. 11: (a) Representative SEM image of the slug thickness, (b) smooth surface of a tensile specimen indicating localised deformation prior to failure, (c) rough surface of a tensile specimen indicating extensive deformation prior to failure and, (d) dimpled fracture surface after tensile testing of the 710 ${ }^{\circ} \mathrm{C}, 15 \mathrm{~s}$ sample with inset showing Ti -rich nitrides. In (b, c) the direction of tensile loading is marked by white arrows 


\section{Figures}

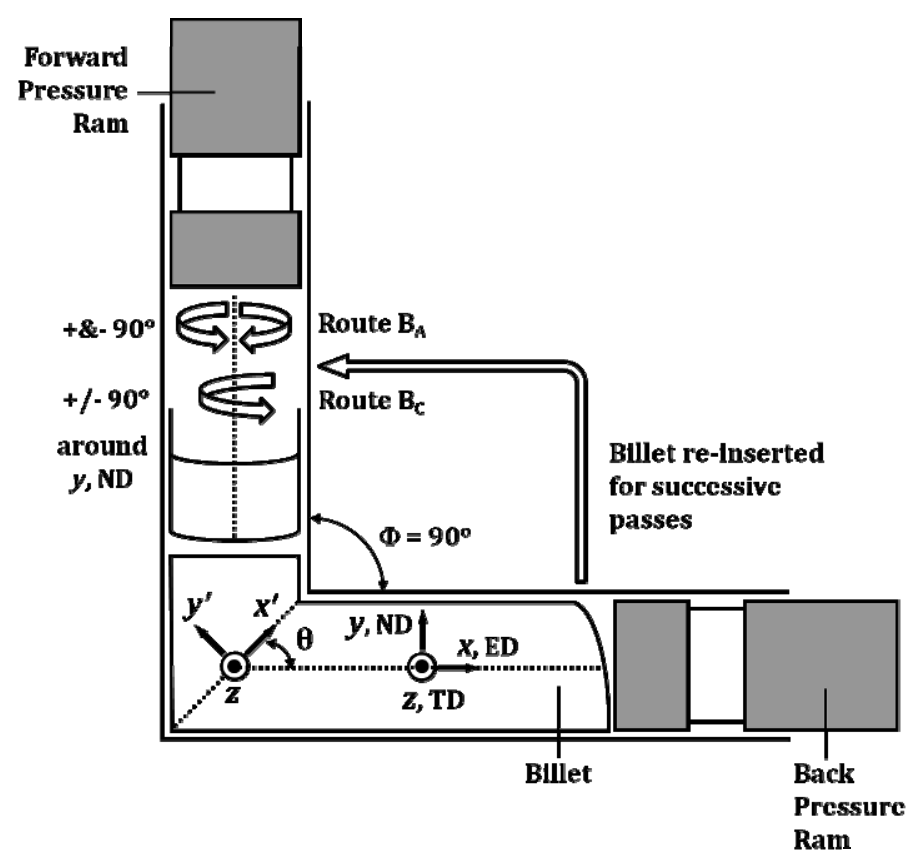

Fig. 1: Schematic representation of the ECAP coordinate system and the billet being re-inserted in the entry channel for successive passes via routes $B_{A}$ and $B_{C}$. $E D=$ extrusion direction, $R D=$ rolling direction, $\mathrm{TD}=$ transverse direction, $\mathrm{ND}=$ normal direction. 

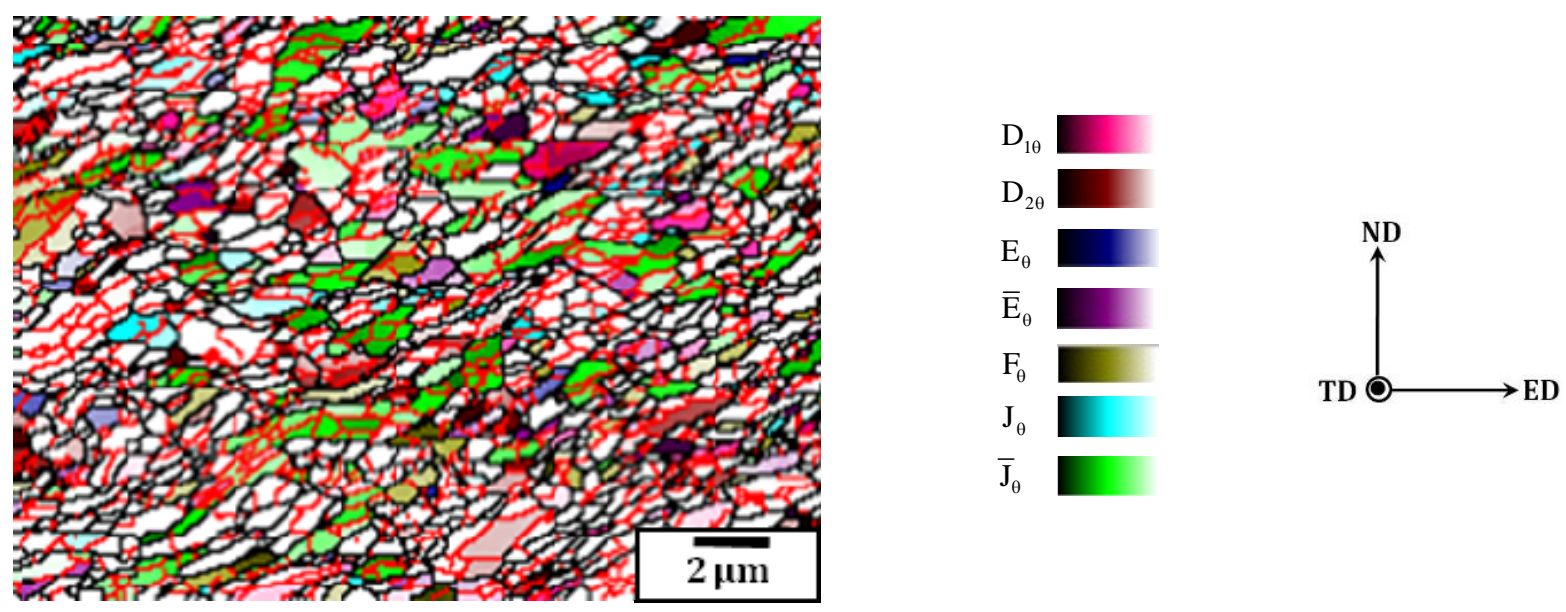

(a)
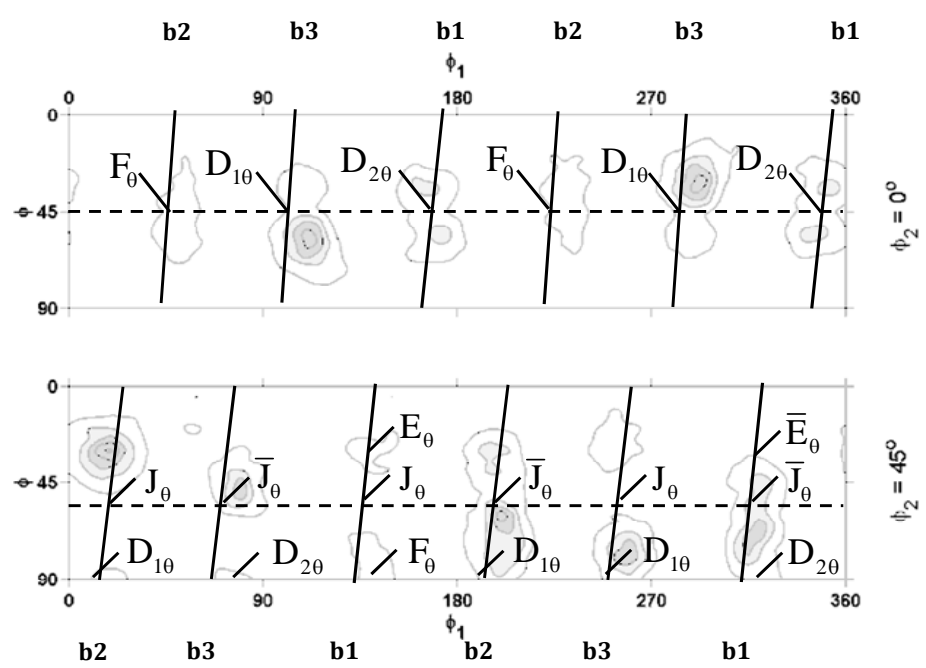

(b)

Fig. 2: (a) Representative EBSD grain boundary maps overlaid with ideal negative simple shear texture components and, (b) $\phi_{2}=0^{\circ}$ and $\phi_{2}=45^{\circ} \mathrm{ODF}$ sections of the micro-texture after ECAP. In (a), red (grey) $=$ LAGBs, black $=$ HAGBs. Contour levels $=1 \times$ random . 


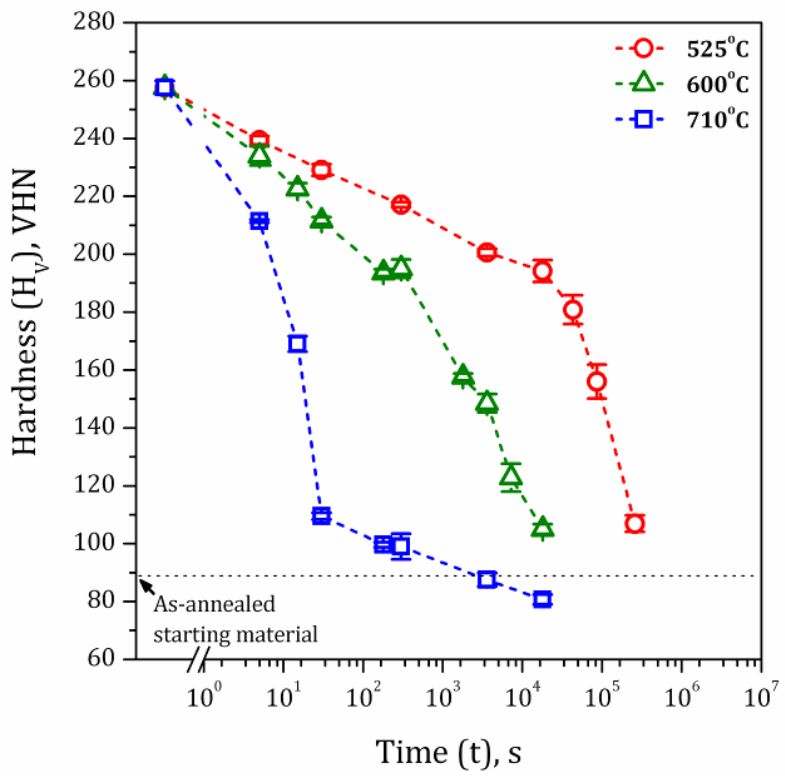

(a)

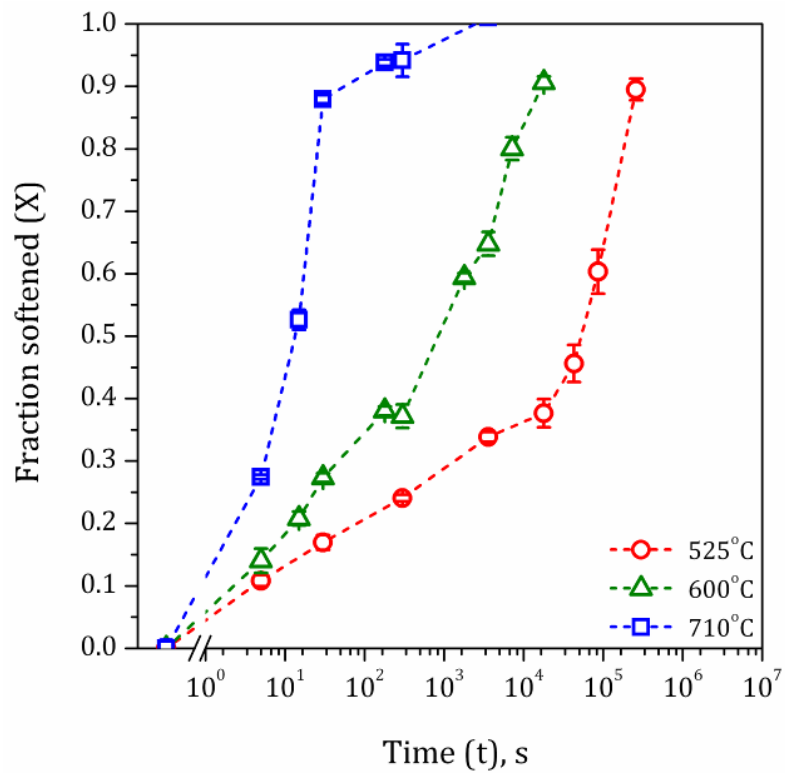

(b)

Fig. 3: (a) Hardness versus annealing time and, (b) fraction softened versus annealing time for isothermal annealing at 525,600 and $710^{\circ} \mathrm{C}$. 


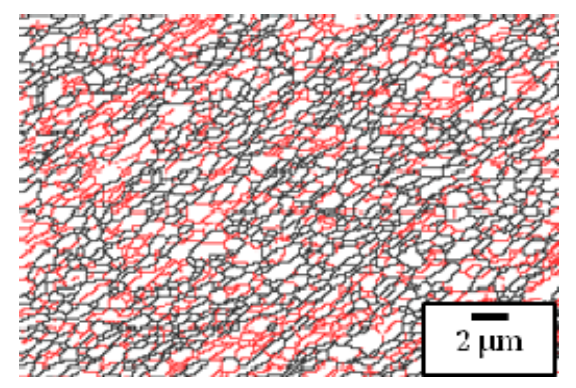

(a)

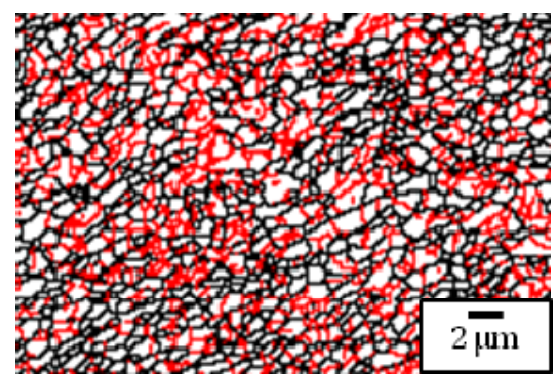

(d)

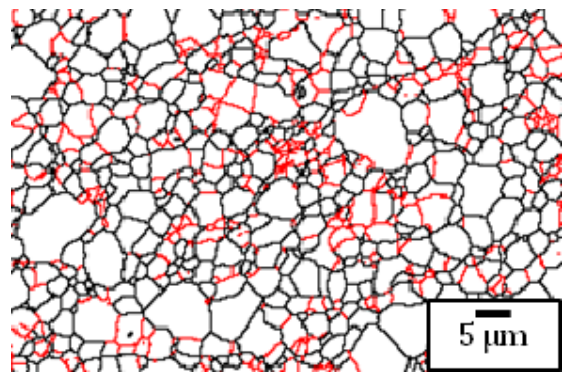

(g)

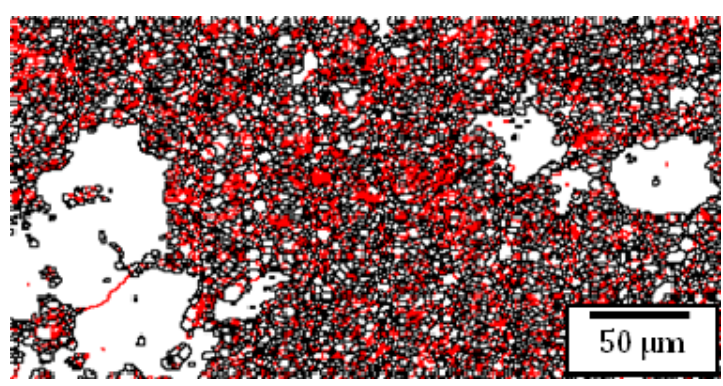

(i)

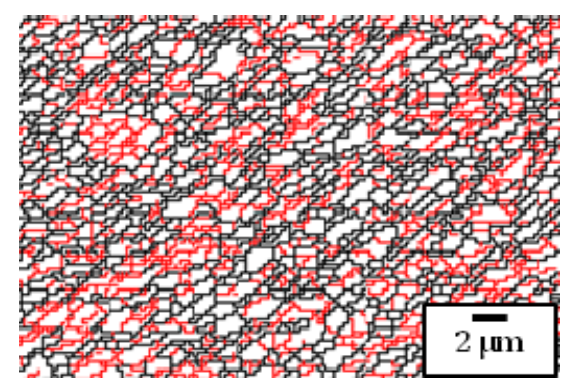

(b)

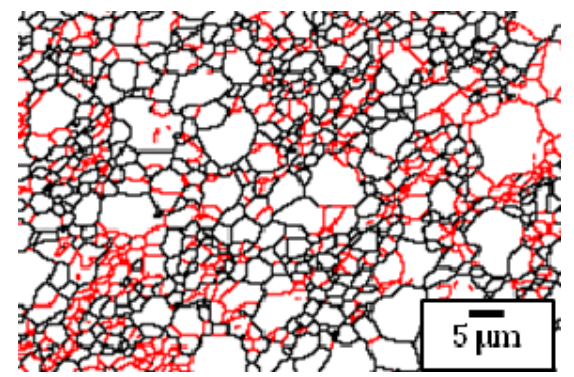

(e)

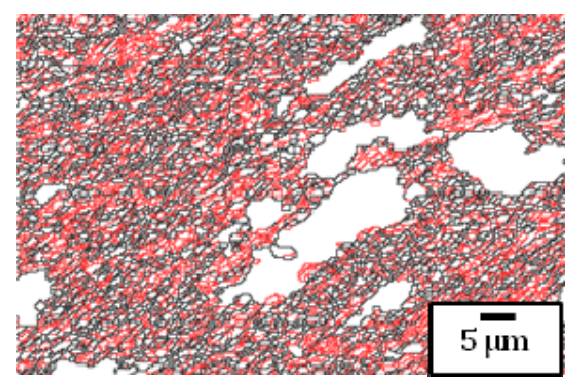

(c)

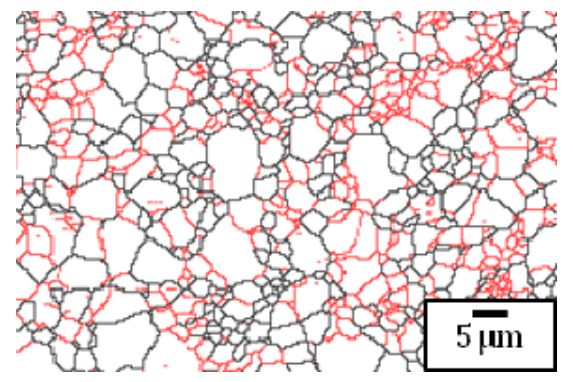

(f)

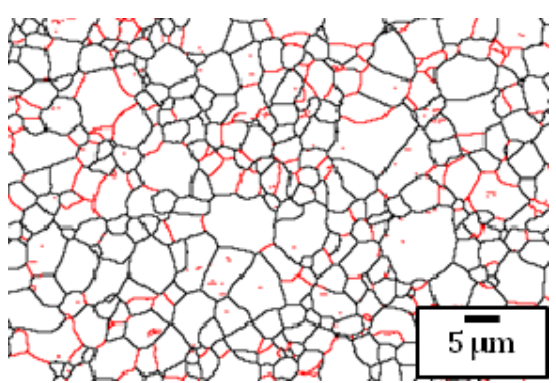

(h)

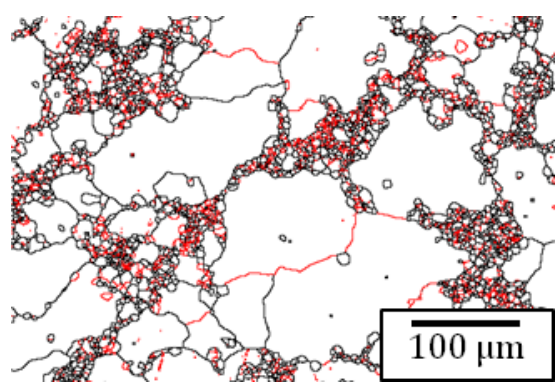

(j)

Fig. 4: Representative EBSD grain boundary maps after annealing at (a-c) $525^{\circ} \mathrm{C}$, (d-f) $600{ }^{\circ} \mathrm{C}$ and (g-j) $710{ }^{\circ} \mathrm{C}$ for: (a) $300 \mathrm{~s}$, (b) $5 \mathrm{~h}$, (c) $72 \mathrm{~h}$, (d) $300 \mathrm{~s}$, (e) $1 \mathrm{~h}$, (f) $5 \mathrm{~h}$, (g) $30 \mathrm{~s}$, (h) $180 \mathrm{~s}$, (i) $300 \mathrm{~s}$ and (j) $1 \mathrm{~h}$. Red (grey) $=$ LAGBs, black $=$ HAGBs. 


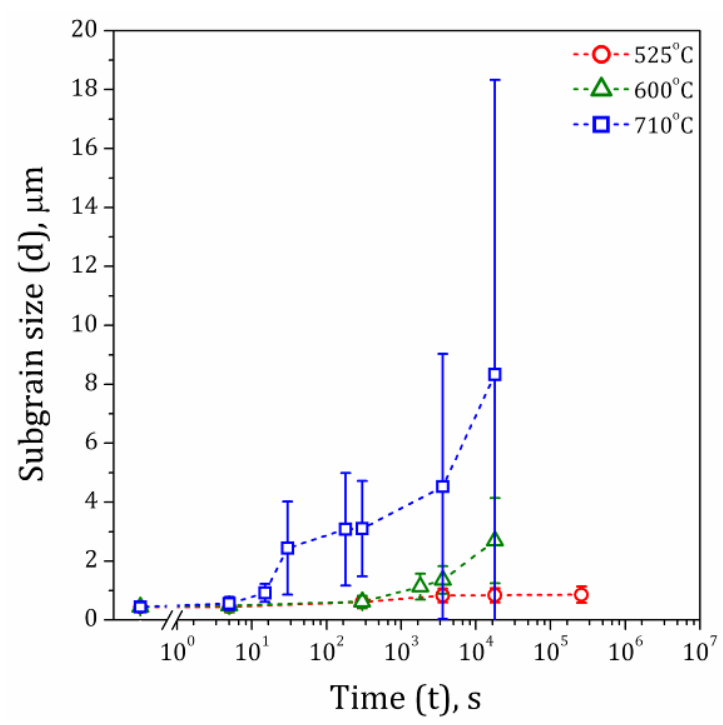

(a)

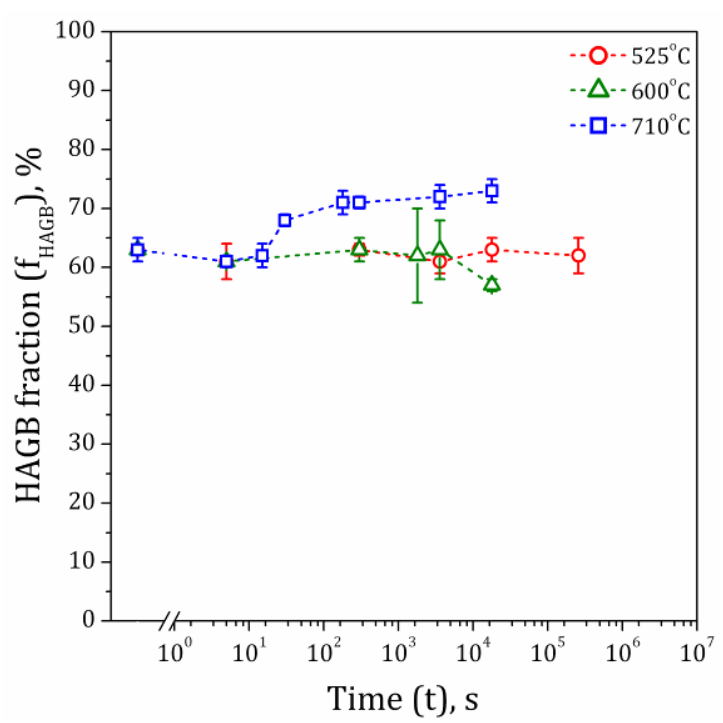

(c)

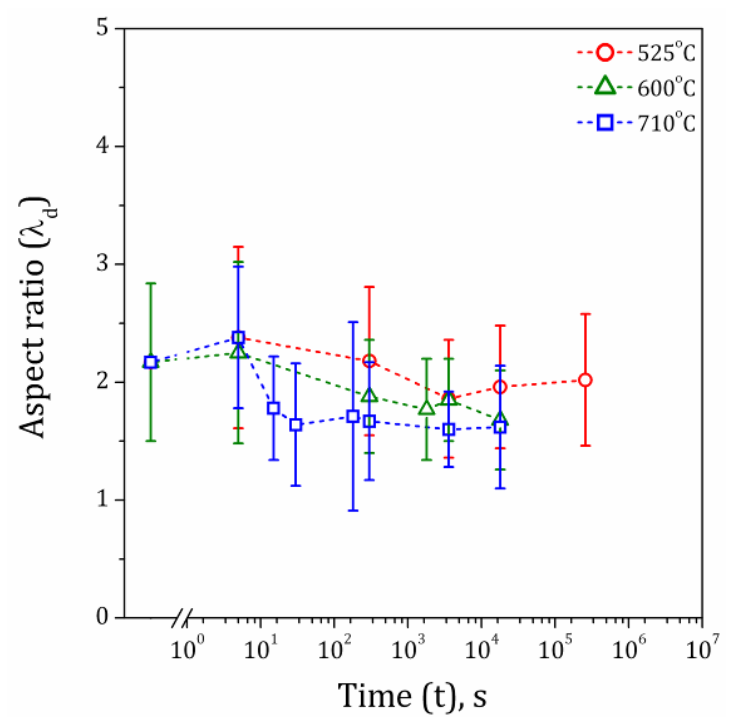

(b)

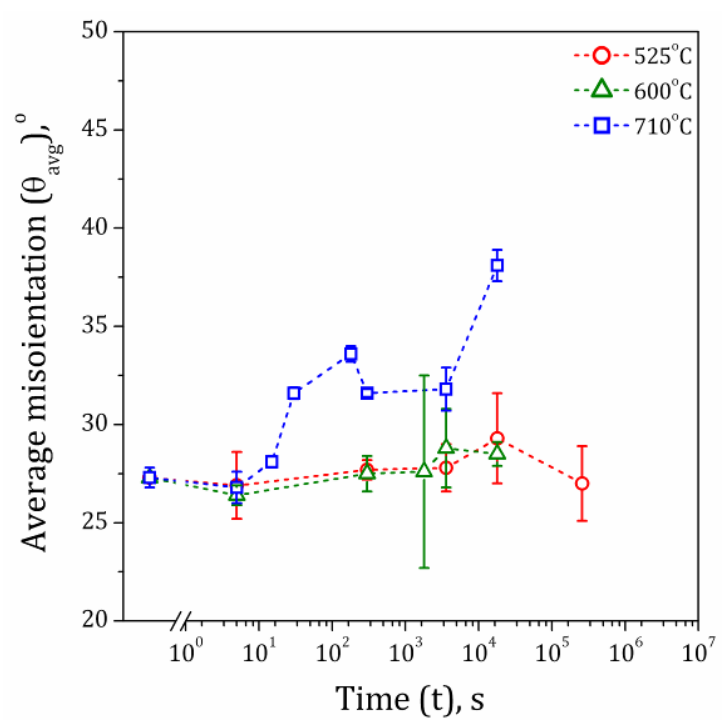

(d)

Fig. 5: Evolution of (a) subgrain size, (b) aspect ratio, (c) HAGB fraction and, (d) average misorientation during isothermal annealing at 525,600 and $710{ }^{\circ} \mathrm{C}$. 


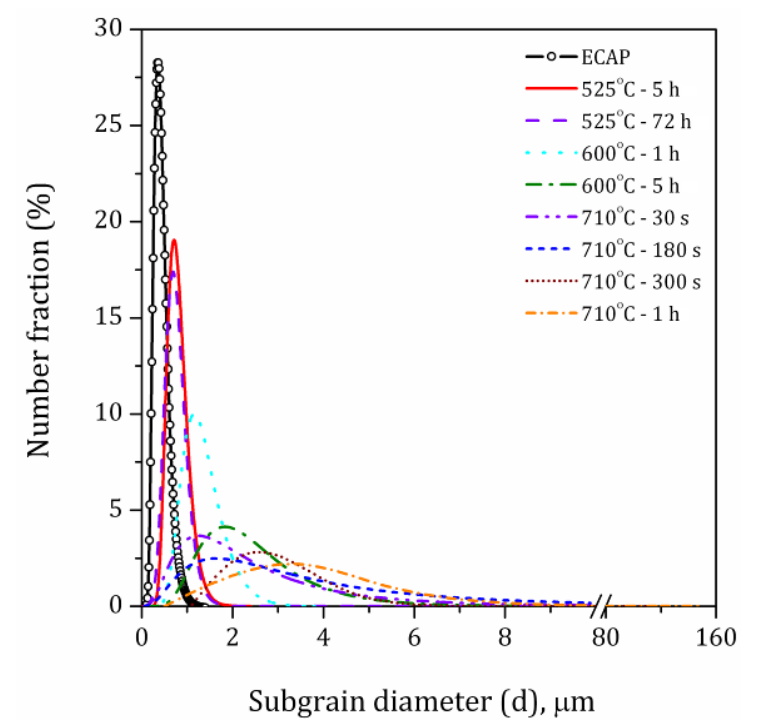

(a)

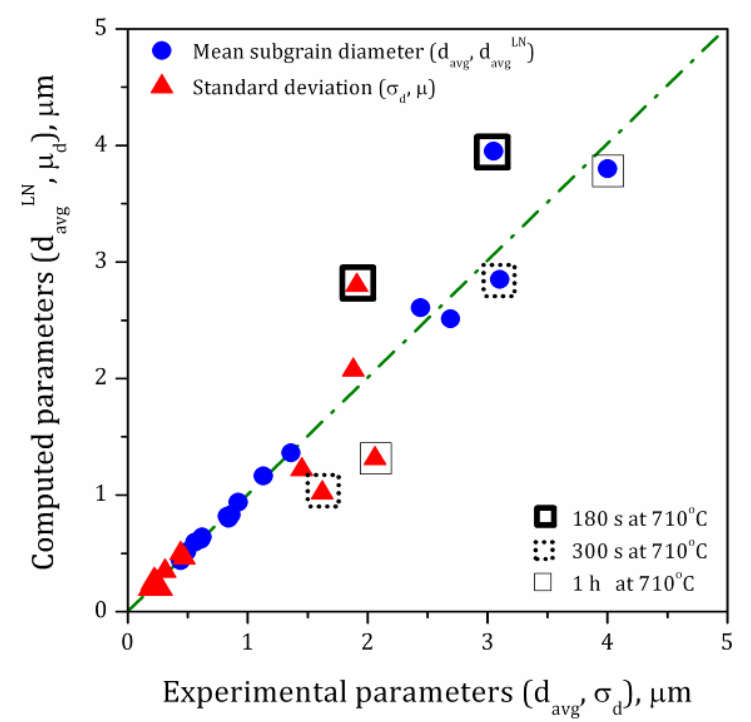

(c)

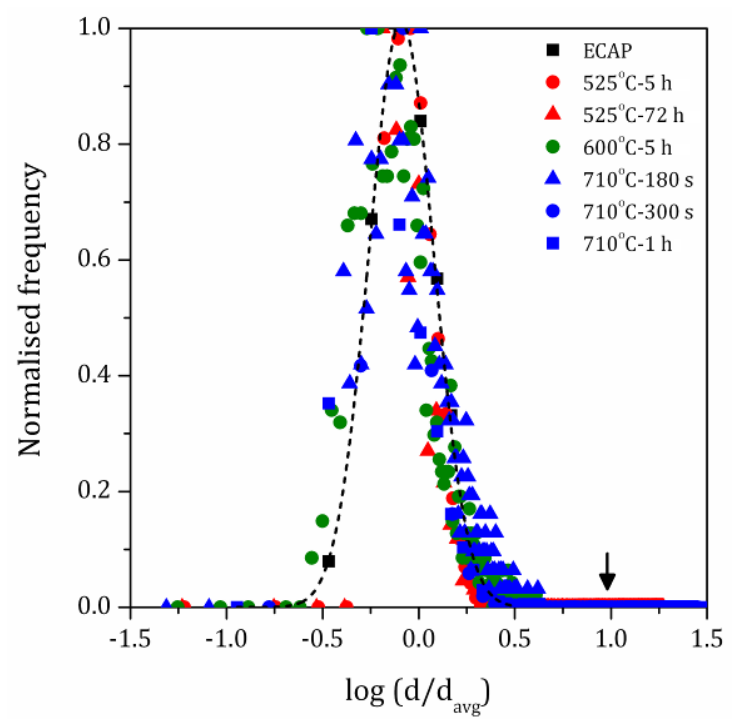

(b)

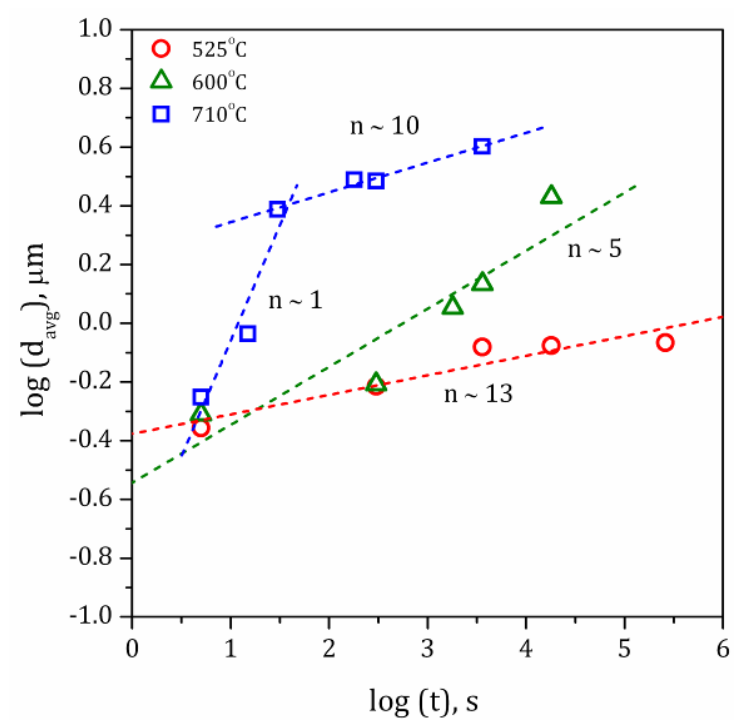

(d)

Fig. 6: (a) Fitted L-N subgrain size distributions, (b) normalised subgrain size distributions, (c) experimental versus computed arithmetic mean and standard deviation of subgrain size distributions and, (d) subgrain growth kinetics during isothermal annealing at 525, 600 and $710{ }^{\circ} \mathrm{C}$. In (b), the arrow marks the tail of the L-N distributions. 


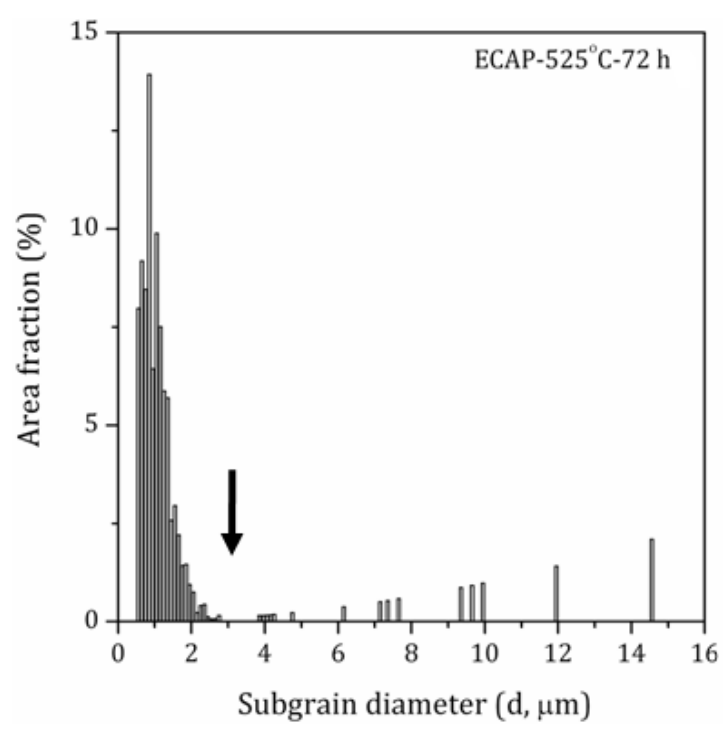

(a)

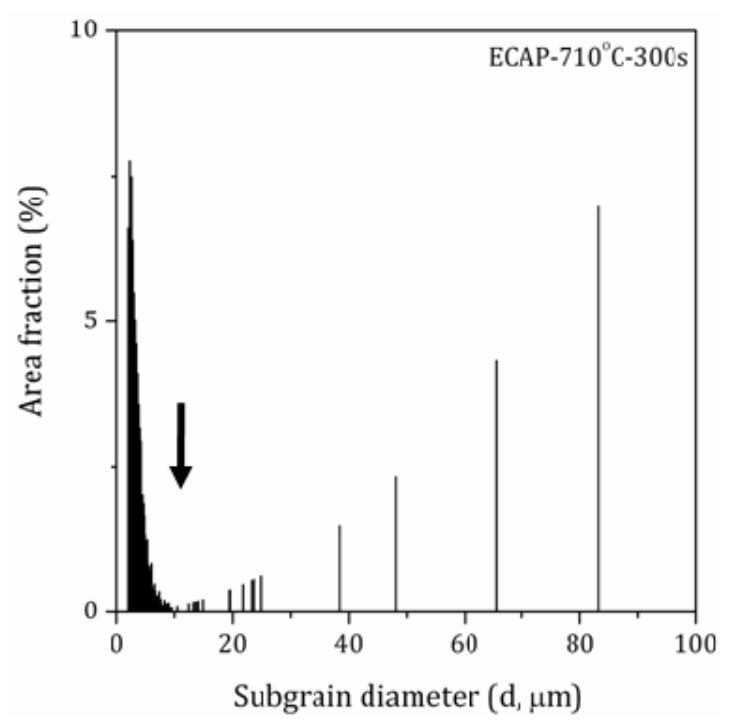

(c)

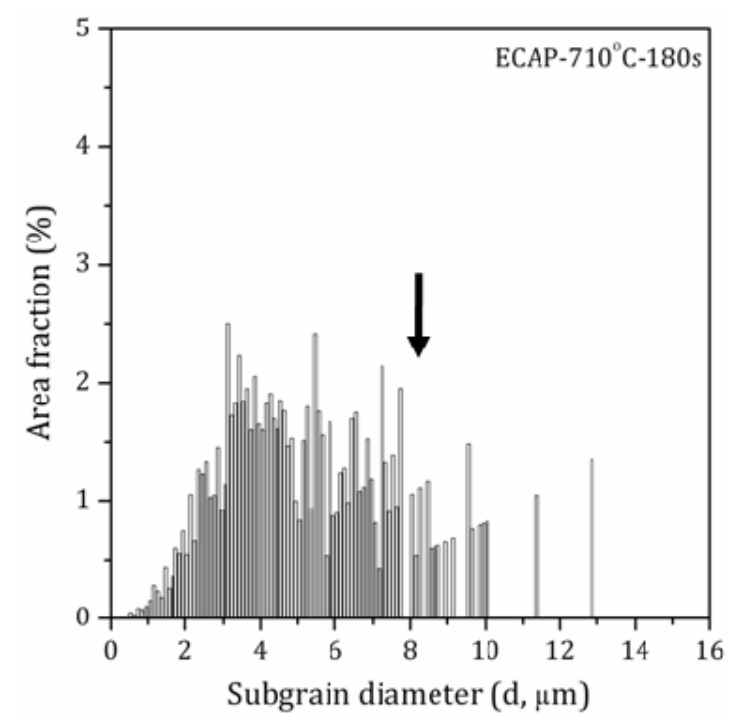

(b)

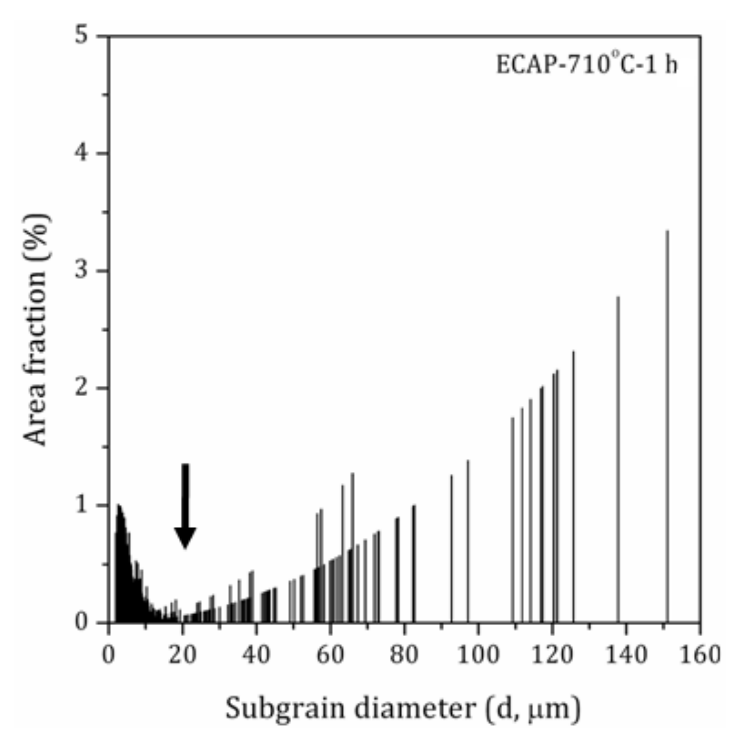

(d)

Fig. 7: Evolution of area-weighted grain size distribution after annealing at (a) $525^{\circ} \mathrm{C}$ for $72 \mathrm{~h}$ and, 710 ${ }^{\circ} \mathrm{C}$ for (b) $180 \mathrm{~s}$ (c) $300 \mathrm{~s}$ and, (d) $1 \mathrm{~h}$. Note that arrows indicate the critical cut-off subgrain size beyond which discontinuous coarsening occurs. 

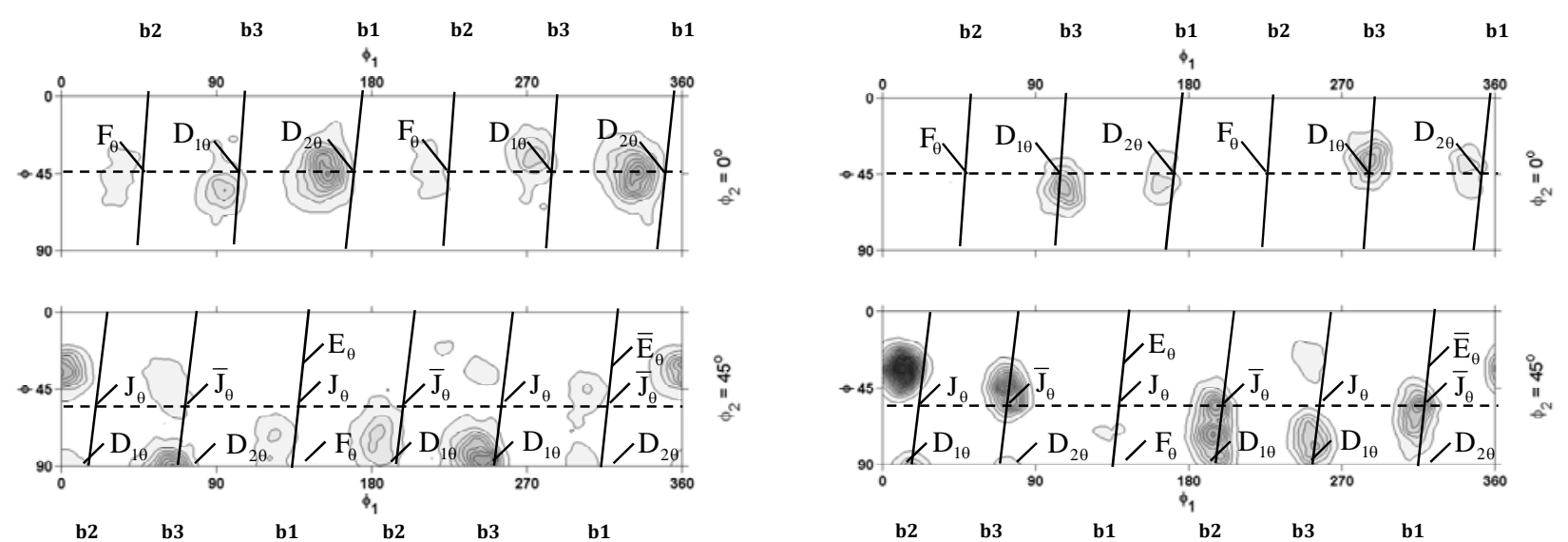

(a)

(b)
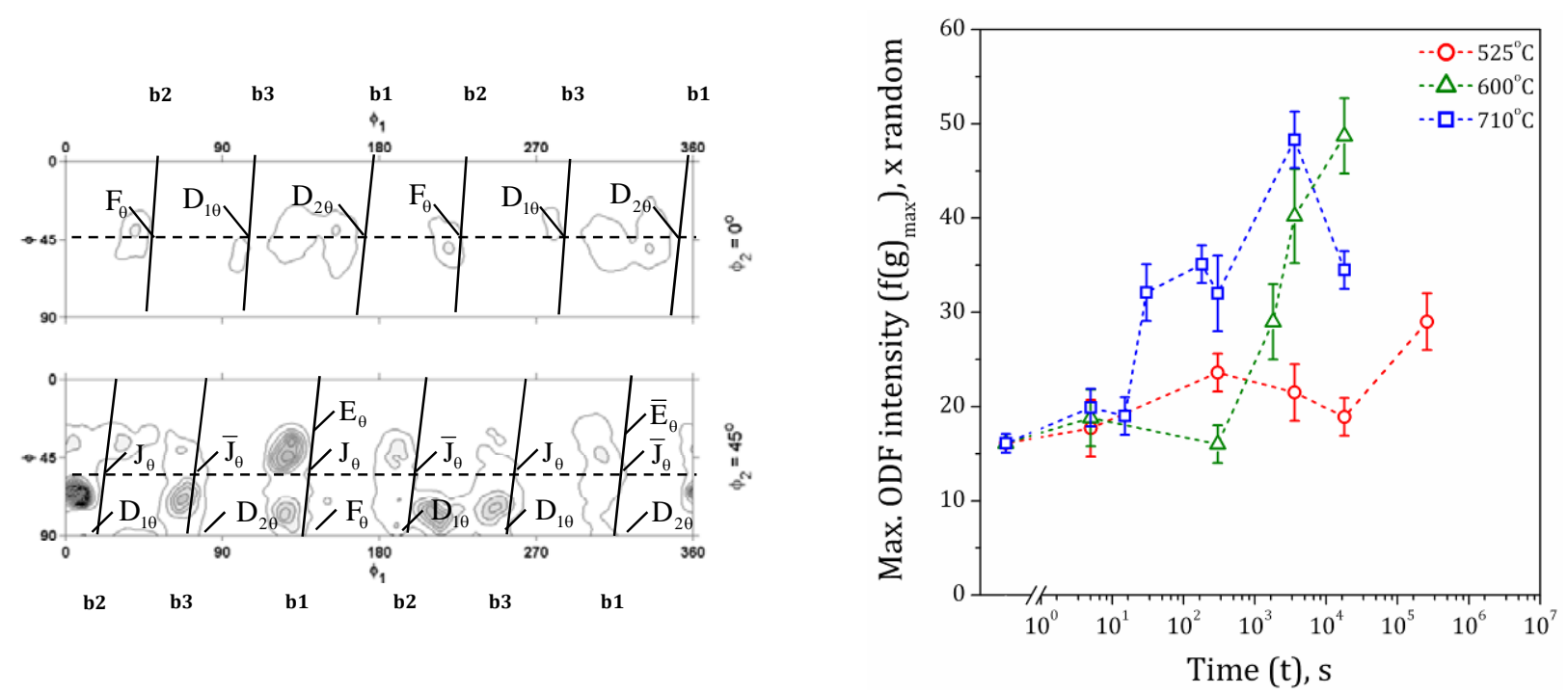

(c)

(d)

Fig. 8: $\phi_{2}=0^{\circ}$ and $\phi_{2}=45^{\circ}$ ODF sections of the micro-texture after annealing at (a) $525^{\circ} \mathrm{C}$ for $72 \mathrm{~h}$, (b) $600{ }^{\circ} \mathrm{C}$ for $5 \mathrm{~h}$, (c) $710^{\circ} \mathrm{C}$ for $5 \mathrm{~h}$ and, (d) maximum ODF intensity $\mathrm{f}(\mathrm{g}$ ) versus annealing time. Contour levels $=1 \times$ random. 


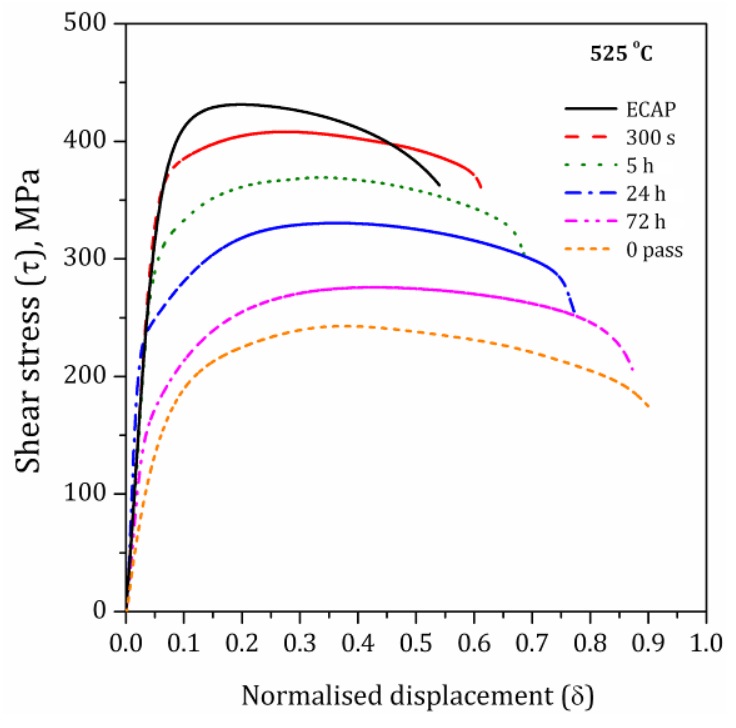

(a)

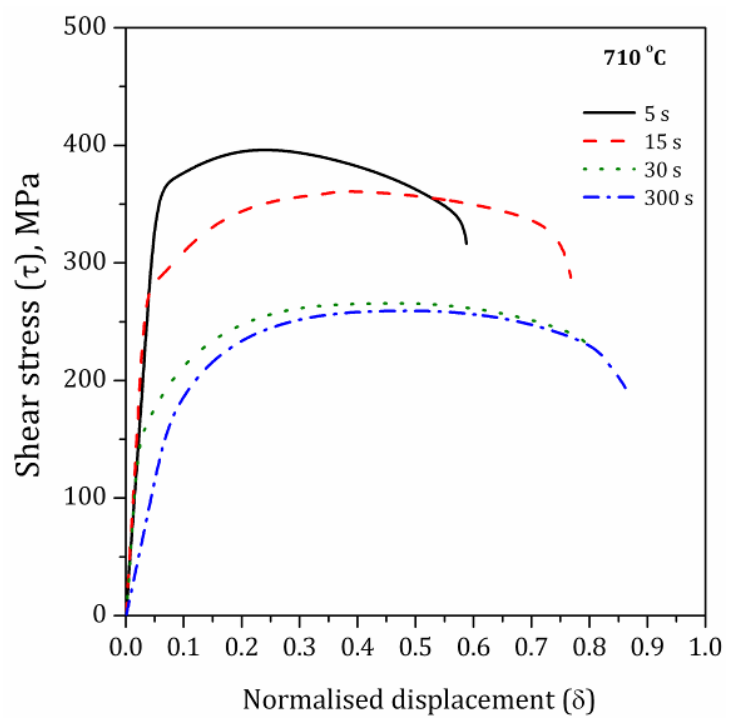

(c)

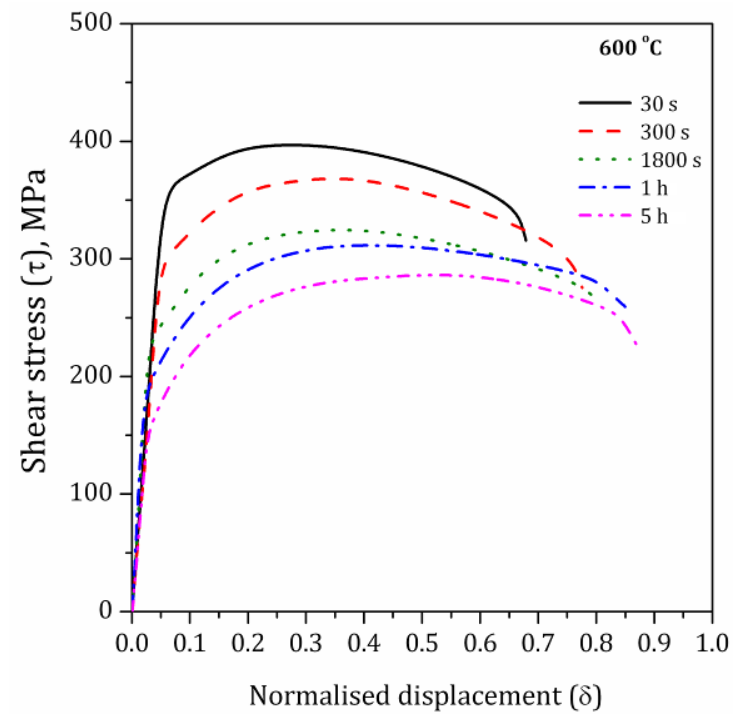

(b)

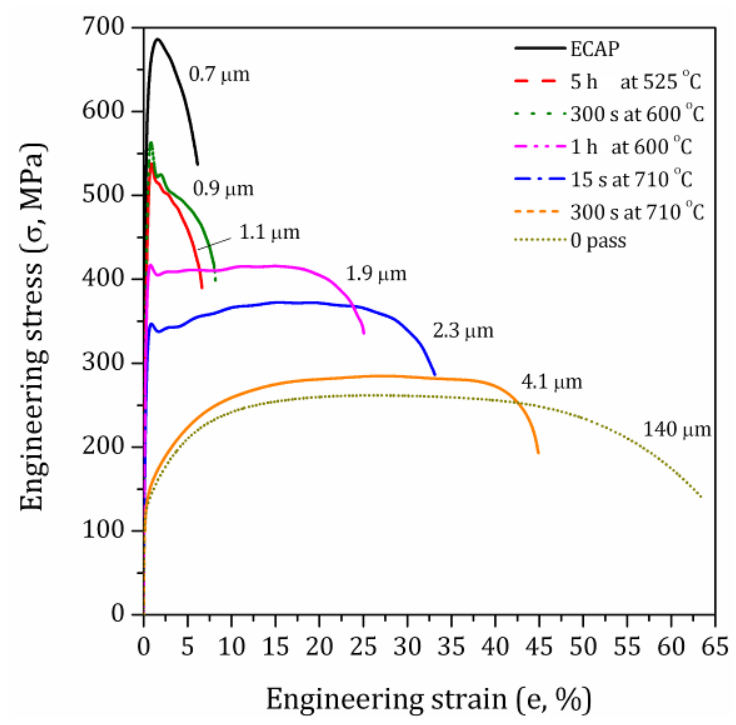

(d)

Fig. 9: Shear stress versus normalised displacement after shear punch testing for (a) 0 pass starting, ECAP and $525{ }^{\circ} \mathrm{C}$, (b) $600{ }^{\circ} \mathrm{C}$, (c) $710{ }^{\circ} \mathrm{C}$ and, (d) engineering stress versus strain after tensile testing for various conditions. Note the average grain diameters in $(d)$. 


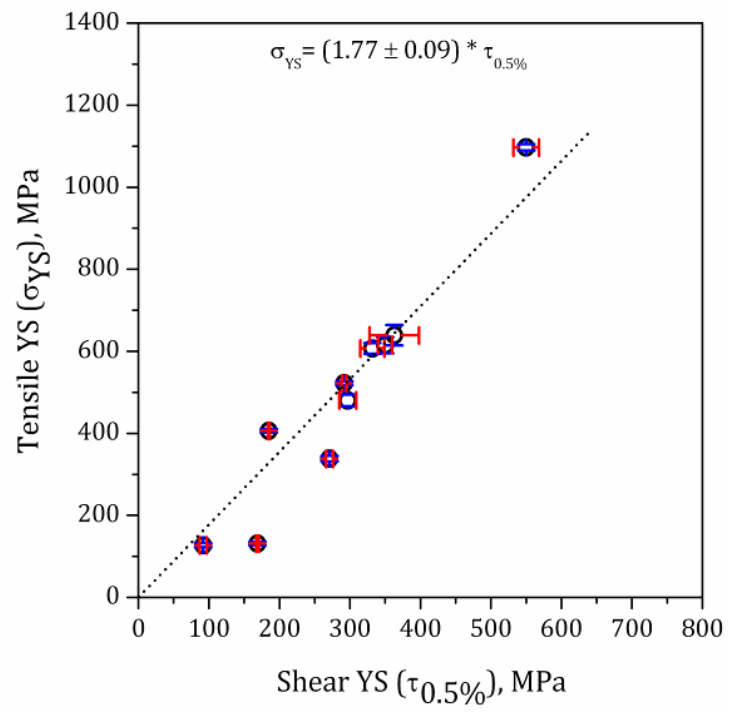

(a)

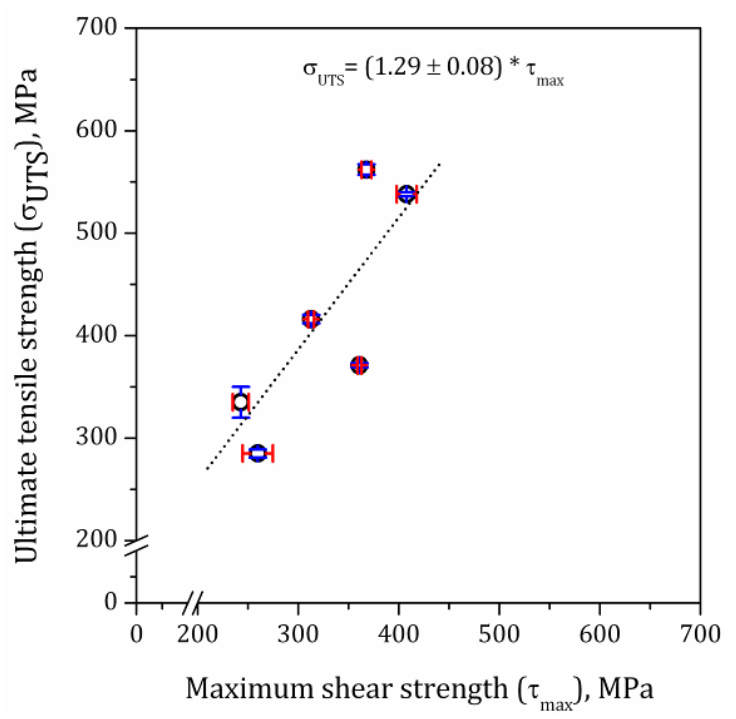

(c)

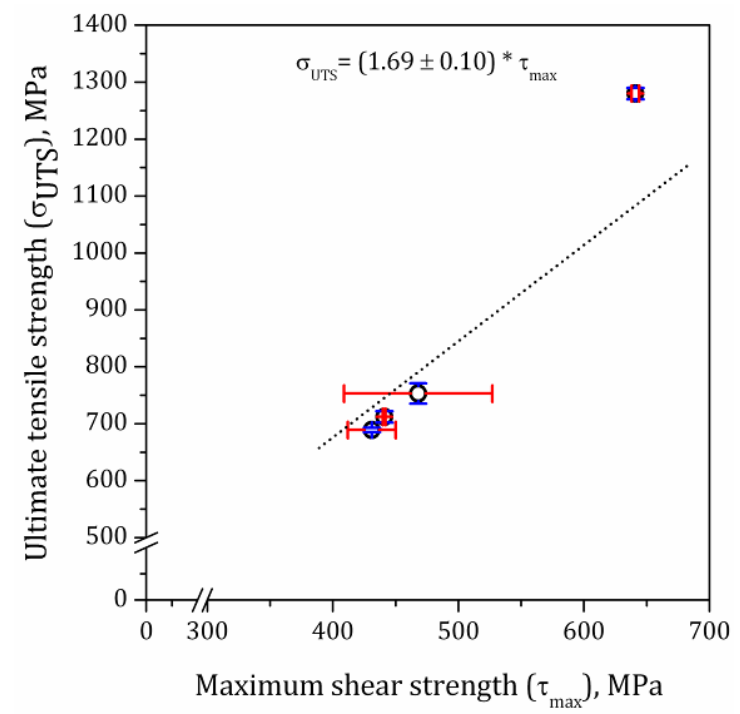

(b)

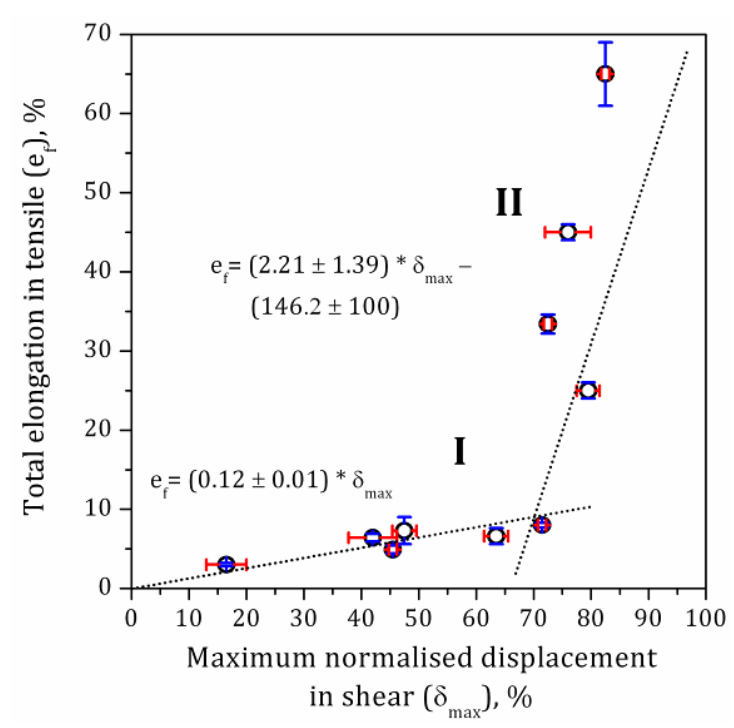

(d)

Fig. 10: Correlations between (a) shear and tensile yield strengths, (b) maximum shear and ultimate tensile strengths after deformation, (c) maximum shear and ultimate tensile strengths after annealing and, (d) total elongation in tension with maximum normalised displacement in shear. 


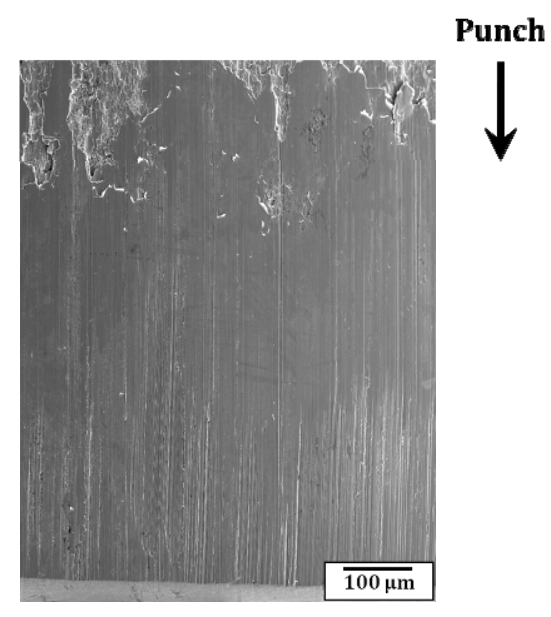

(a)

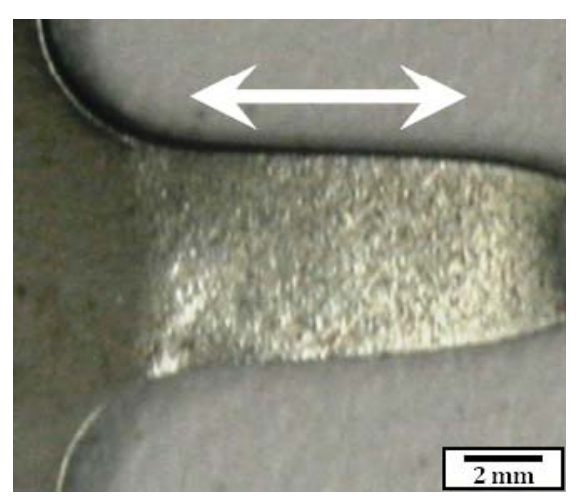

(c)

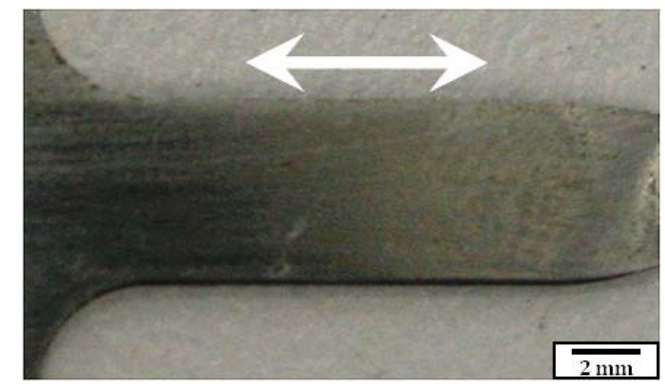

(b)

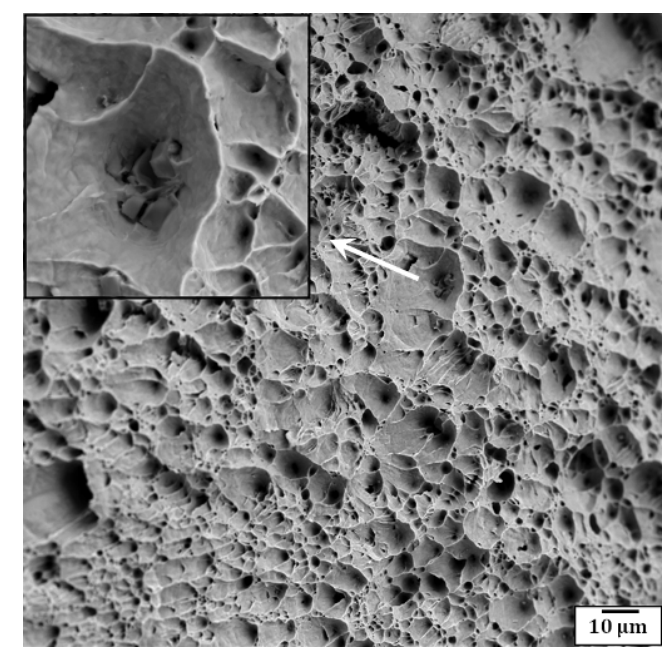

(d)

Fig. 11: (a) Representative SEM image of the slug thickness, (b) smooth surface of a tensile specimen indicating localised deformation prior to failure, (c) rough surface of a tensile specimen indicating extensive deformation prior to failure and, (d) dimpled fracture surface after tensile testing of the 710 ${ }^{\circ} \mathrm{C}, 15 \mathrm{~s}$ sample with inset showing Ti -rich nitrides. In (b, c) the direction of tensile loading is marked by white arrows. 